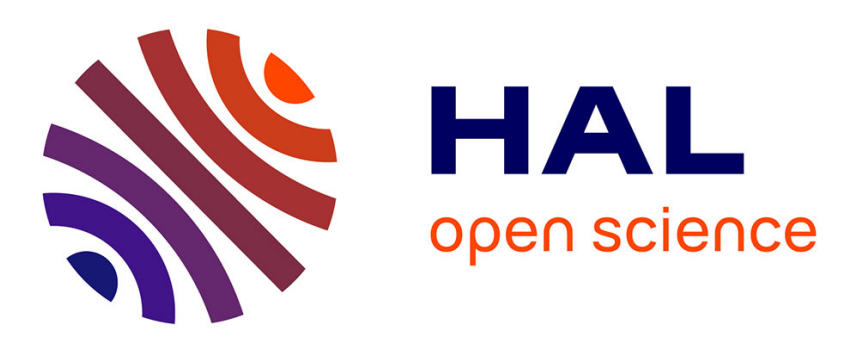

\title{
Nanocavitation mechanisms in deformed High Density PolyEthylene (HDPE) using synchrotron radiation NanoTomography
}

Cristian Ovalle, Peter Cloetens, Henry Proudhon, Thilo F. Morgeneyer, Lucien Laiarinandrasana

\section{To cite this version:}

Cristian Ovalle, Peter Cloetens, Henry Proudhon, Thilo F. Morgeneyer, Lucien Laiarinandrasana. Nanocavitation mechanisms in deformed High Density PolyEthylene (HDPE) using synchrotron radiation NanoTomography. Polymer, 2021, 229, pp.123959. 10.1016/j.polymer.2021.123959 . hal03288721

\section{HAL Id: hal-03288721 \\ https://hal.science/hal-03288721}

Submitted on 16 Jul 2021

HAL is a multi-disciplinary open access archive for the deposit and dissemination of scientific research documents, whether they are published or not. The documents may come from teaching and research institutions in France or abroad, or from public or private research centers.
L'archive ouverte pluridisciplinaire $\mathbf{H A L}$, est destinée au dépôt et à la diffusion de documents scientifiques de niveau recherche, publiés ou non, émanant des établissements d'enseignement et de recherche français ou étrangers, des laboratoires publics ou privés. 


\title{
Nanocavitation mechanisms in deformed High Density PolyEthylene (HDPE) using Synchrotron Radiation NanoTomography
}

\author{
Cristian Ovalle ${ }^{a, *}$, Peter Cloetens ${ }^{b}$, Henry Proudhon ${ }^{a}$, Thilo F Morgeneyer ${ }^{a}$ and \\ Lucien Laiarinandrasana ${ }^{a}$
}

${ }^{a}$ MINES ParisTech, PSL University, Centre des Matériaux (CMAT), CNRS UMR 7633, BP 8791003 Evry, France

${ }^{b}$ European Synchrotron Radiation Facility, BP 220, F-38043 Grenoble Cedex, France

\section{ARTICLE INFO}

\section{Keywords:}

HDPE

Nanocavitation

NanoTomography

\begin{abstract}
A B S T R A C T
The nanocavitation distribution in deformed High Density PolyEthylene (HDPE) was investigated. A flat notched sample of HDPE, deformed under steady crosshead speed up to the end of the stress softening, was observed by classical synchrotron parallel beam microtomography and magnified holotomography with a true spatial resolution of $0.7 \mu \mathrm{m}$ and $0.05 \mu \mathrm{m}$, respectively. Image processing, 3D image segmentation and 2D-Fast Fourier Transform, were shown to lead to quantification of void volume fraction and void size distributions. Nanocavitation morphology and distribution in HDPE reveals to be similar to cavitation mechanisms in other semi-crystalline polymers, but at a different scale. While a slight decrease of the void diameter was seen, from the end of the neck shoulder to the extended neck region, a significant increment of the height was evidenced. Furthermore, the results provide compelling evidence of morphology transition of cavities within the test sample from an oblate to a prolate geometry.
\end{abstract}

\section{Introduction}

In order to ensure in-service robustness and to predict the durability of components made of semicrystalline polymers, identifying reliable and consistent constitutive models is of prime importance. Macroscopic mechanical behaviour is commonly characterized by the stress-strain curve obtained from uniaxial tests. Taking into account the pressure sensitivity of semicrystalline polymers [1,2], tensile tests under hydrostatic pressure or compressive tests have been performed $[3,4,5]$. However, uniaxial tests are not sufficient to analyse this pressure sensitivity, except when studying the necking process [6].

In smooth samples, necking originates in a non-controlled location during uniaxial loading. As a consequence of this geometrical irregularity, a multiaxial stress state within the net cross section of the sample is induced. In notched samples, the multiaxial stress state is theoretically characterized [7] and re-necking, limited to the notched section, could be expected. The multiaxial stress state consists of high levels of hydrostatic stress, for which polymers are known to be sensitive $[8,9,10]$. Besides, constitutive equations should be regarded as an additive decomposition of shear and hydrostatic pressure, i.e. shear stress with respect to shear strain and hydrostatic pressure versus volume change. Attention is paid here to this latter which is directly related to the cavitation evolution.

Associated commonly with cavitation mechanisms taking place at the microscopic scale within the material, whitening developing during necking appears on smooth samples, respectively re-necking on notched samples, at the peak stress of the engineering stress-strain curve $[6,11,12]$. Microscopic examinations of the deformed microstructure of polymers exhibit voiding, inducing volume change within the material. Many studies have been reported widely on PA6 [13, 14, 15, 16], PP [17], PVDF [18, 19], PA11 [20, 21] and PE [12, 22, 23, 24, 25, 26] using notched samples and $3 \mathrm{D}$ imaging to better understand the cavitation mechanisms on semicrystalline polymers.

Examinations of the microstructure and damage in the necking region via synchrotron radiation tomography revealed elongated voids in deformed PA6 [13]. Indeed, further analyses highlighted unbroken walls separating voids aligned in columns. In [14], ex-situ tests at different stages of deformation on the load versus applied displacement curve - peak stress, after the postyielding stress decrease (end of stress softening) and at the end of the plateau prior

*Corresponding author

@ cristian.ovalle_rodas@mines-paristech.fr (C. Ovalle)

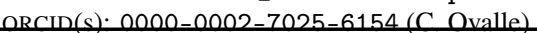


to the final rupture - were performed in notched round PA6 samples. The void growth and void morphology, i.e. void anisotropy, was studied. According to the authors, polar fans were the origin of void column shapes within the spherulitic microstructure. Additionnaly, the observations highlighted the presence of penny shaped cavities, i.e. voids in which $\phi>h$ where $\phi$ and $h$ are respectively the void diameter and height, at the peak stress; unchanged $\phi$ but increasing $h$ at the end of the stress softening; decreasing $\phi$ and still increasing $h$ during the stress plateau. These results were obtained with tomography at a $0.7 \mu \mathrm{m}$ resolution since the microstructure of the PA6, the spherulite mean diameter was about $6 \mu \mathrm{m}$, allowed it. By contrast, for PE, spherulitic microstructure is difficult to observe due to its glass transition temperature $\mathrm{T}_{g}$ and smaller spherulite size. Attempt was made by Blaise et al. [22] to study PE with a spatial resolution slightly below $1 \mu \mathrm{m}$. Combining analysis in real space, using light scattering experiments (IPSLT technique), and in the reciprocal space, using the Fast Fourier Transform analysis (FFT), led to the conclusion that the density contrasts were related essentially to macromolecular rearrangement, associated with crazing, but without cavitation.

In this paper, the magnified synchrotron radiation nano(holo)tomography was used to study the existence of permanent nano-cavities within the spherulitic microstructure of HDPE; furthermore, the motivation of this work was to show that the cavitation mechanisms are the same as in the PA6 but at a lower scale. A flat notched sample of semicrystalline HDPE was deformed under steady crosshead speed up to the end of the first stress softening. The microstructure and the voiding state in the unloaded sample was observed in 3D at the European Synchrotron Radiation Facility (ESRF). Two parallel regions were studied: four locations of interest near the notch edge and three locations of interest centred on the longitudinal axis, through the necked zone up to the un-necked zone with a particular focus on the neck shoulder, with a resolution of $0.7 \mu \mathrm{m}\left(\mathrm{HDPE}_{0.7}\right)$ and $0.05 \mu \mathrm{m}\left(\mathrm{HDPE}_{0.05}\right)$, respectively. Firstly, a qualitative study on the evolution of the distribution and morphology of cavities along the longitudinal axis was carried out. To better analyse the qualitative data, the results of both the $\mathrm{HDPE}_{0.7}$ and $\mathrm{HDPE}_{0.05}$ were compared with the axial evolution of the microstructure in PA6, from previous works [15]. The qualitative study showed that the cavitation mechanisms in HDPE are the same as in the PA6 but at a lower scale. Secondly, using two different procedures at both the real intensity and reciprocal space, respectively by image segmentation and 2D Fast Fourier Transforms (FFT), a quantitative study of the evolution of the cavities characteristic dimensions was performed.

The paper is organized as follows: The first part of the paper presents the material under study. The experimental techniques and procedures are then presented in terms of the 3D data acquisition and treatment. Results of the microstructure inspections, enriched by a comparative study of the morphology of cavities in PA6, are then presented. Prior to the concluding remarks, discussion about the quantitative evolution of the void characteristic dimensions, supported by the experimental data collected and treated in the previous sections, takes place.

\section{Material and microstructure}

\subsection{HDPE polymer}

The material under study is a stabilized Irgafos 168 polyethylene provided by Veolia. The material was supplied as injected moulded plates. Details about the physico-chemical properties of the semi-crystalline polymer were published in previous works [27, 28, 29], the main ones being recalled here. The High Density PolyEthylene (HDPE) under study has a glass transition temperature $T_{g} \leq-100{ }^{\circ} \mathrm{C}$. Indeed, distinct values of the transition which can be identified as the glass transition temperature were reported previously in the literature $[30,31,32]:-30 \pm 15{ }^{\circ} \mathrm{C},-80 \pm 10^{\circ} \mathrm{C}$ and $-128 \pm 5^{\circ} \mathrm{C}$; however, in this work, the testing temperature (room temperature) is considered to be well above the $\mathrm{T}_{g}$ of the HDPE. Differential Spectroscopy Calorimetry (DSC) yield a cristallinity index of about 55\%. Using thermo-gravimetric analysis, a $2.2 \%$ of carbon black content and a negligible amount of catalytic residues were found. The density value was close to 0.943 . The main material characteristics of the HDPE are summarized in Table 1.

Table 1

HDPE material characteristics: Crystallinity ratio $(\mathrm{XC})$, weight average molar mass (Mw), polydispersity index (IP), and carbon black content [27].

\begin{tabular}{cccc}
\hline$X C$ & $M w$ & $I P$ & carbon black content \\
\hline $55 \%$ & $203 \mathrm{~kg} / \mathrm{mol}$ & 20,3 & $2.2 \%$ \\
\hline
\end{tabular}




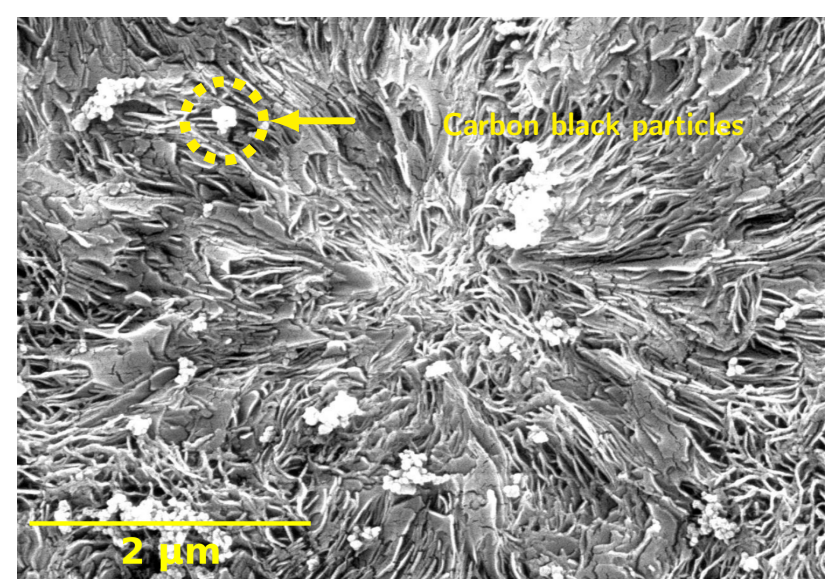

Figure 1: SEM micrograph of the microstructure after permanganic etching.

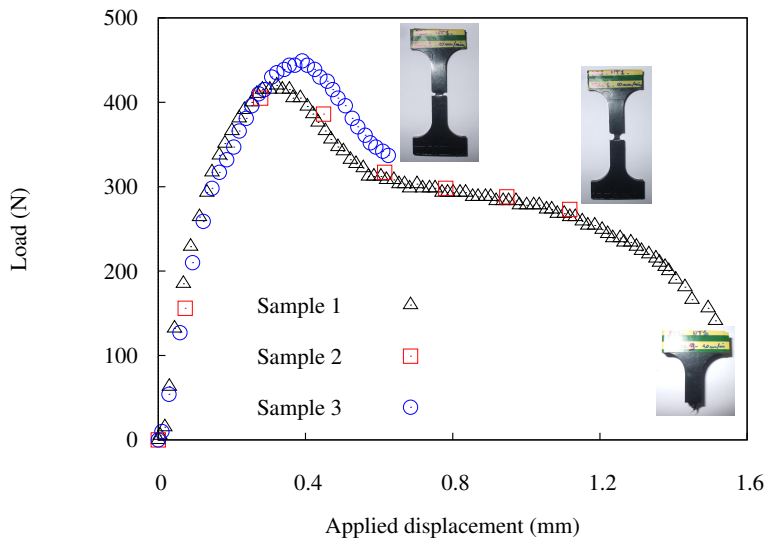

Figure 2: Tensile test response of HDPE notched flat samples at $10 \mathrm{~mm} / \mathrm{min}$. Studied sample $=$ Sample 3, i.e. the one interrupted at the end of the first softening.

\subsection{Microstructure}

In order to highlight the expected semi-crystalline microstructure, a cryo-microtomed and chemically etched sample was examined by Scanning Electron Microscopy (SEM). The SEM micrograph of the microstructure, displayed in Figure 1, revealed the lamellar structure of the crystallite. A spherulite of about $4 \mu \mathrm{m}$ is shown; nonetheless, using several micrographs, an average diameter of about $2 \mu \mathrm{m}$ was estimated [33]. White particles on the surface are believed to be carbon black particles. An average diameter of between 0.1 and $0.2 \mu \mathrm{m}$ was determined [33]. One example of carbon black particles is surrounded by a yellow dashed line in Figure 1. These particles may act as nucleation site for cavities as a consequence of the particle/polymer matrix interactions [34].

\subsection{Flat notched sample}

Flat samples were cut out from injected moulded plates with $4 \mathrm{~mm}$ thickness [27]. The deformed sample geometry can be observed in Figure 2. Sample longitudinal axis corresponds to the injection direction. Notched samples with an initial notch root radius $\rho=1 \mathrm{~mm}$, a notch depth $a=2 \mathrm{~mm}$, a notch depth ratio $a / W$ of 0.5 ( $W=4 \mathrm{~mm}$ being the half-width of the sample), and an initial vertical distance between the notch shoulders $\delta_{0}=2 \mathrm{~mm}$ were used. The advantage of such geometry is that a, theoretically characterized [7], higher triaxial stress state conducting to enhance void growth is expected at the cross section in the notched region of the sample. Furthermore, the sample geometry takes into consideration the ductility of the material and the narrow maximal travel of the testing machine. 


\section{Methodology}

\subsection{Ex-situ tensile test}

To assess repeatability, three monotonic tensile tests were run under a crosshead speed of $10 \mathrm{~mm} / \mathrm{min}$ using an electromechanical testing machine provided with a load cell at room temperature $\left(20^{\circ} \mathrm{C}\right)$ and at a relative humidity of 50\%. The response curve, i.e. the load $F$ plotted against the crosshead displacement $L$, is given in Figure 2. Prior to the peak load, HDPE samples exhibited an approximately linear response followed by flow load. At the end of the first softening, associated with the re-necking of the notched zone, a marginal second softening before failure was evidenced. Similar results for HDPE have been observed [28, 35, 36, 37]. Tensile tests were interrupted at three different characteristic displacements: i) up to failure; ii) at the end of the plateau; and iii) at the end of the first softening; then, the samples were unloaded. Only the last sample was studied by radiation tomography. The tomography scanning was carried out six months after the tensile experiments, therefore only permanent cavitation was studied.

\subsection{Nano(holo)tomography}

For the first observation, near the notch edge, standard parallel beam synchrotron radiation tomography has been carried out at the European Synchrotron Radiation Facility (ESRF), beamline ID19. Details about the classical synchrotron parallel beam microtomography can be found elsewhere [38], the main ones being recalled here. In our case, an energy of $17.6 \mathrm{keV}$ and a voxel size of $0.7 \mu \mathrm{m}$ have been used. In the best cases, the microtomography spatial resolution can not go easily below $0.5 \mu \mathrm{m}$. This resolution limit might not be good enough to allow us to visualize very fine damage features of our material.

To overcome this limitation, magnified holotomography [39], carried out at ESRF (beamline ID22), was used for the second observation, centred at the longitudinal axis. The principle of this improvement is to create an intense and divergent X-ray beam and to use the divergence to magnify the projections by simply moving a classical detector (2 $\mu \mathrm{m}$ pixel size can be enough) away from the focal point. In this study, we have used a set-up where a KirkpatrickBaez optics system focuses the initially parallel synchrotron beam down to a focal spot below $100 \mathrm{~nm}$ in lateral size. The multilayer coated optics also selects from the initially pink beam a narrow energy band around $29.6 \mathrm{keV}$. Each holotomography scan was composed of four tomography acquisitions at different distances between the focal point and the sample. For each scan, 2000 projections were acquired over 360 degree and the exposure time per frame was 0.25 s. More details on the set-up can be found in Bleuet et al. [40]. A voxel size of $0.05 \mu \mathrm{m}$ have been used.

\subsection{Tomographic Volumes of Interest}

The notched zone of the studied sample can be found in Figure 3, width and thickness views being displayed respectively in Figures 3.a and 3.b. A whitened zone, commonly associated with the presence of voids [18, 41], was observed in the centre of the sample surface, see Figure 3.a. As evident from Figure 3.b, through-thickness necking in the notched zone was observed, presumably due to heterogeneous deformation in this region. A diabolo-shaped profile was highlighted, i.e. a higher and constant contraction in the centre of the sample. Similar observations, in semi-crystalline polymers, have been mentioned in previous works [24, 42, 43].

Approximate locations of the Tomographic Volumes-Of-Interest (TVOI) are highlighted in Figure 3.a. Two parallel regions were observed: four locations of interest near the notch edge (blue rectangle boxes) and three locations of interest centred on the longitudinal axis (red square boxes) with a resolution of $0.7 \mu \mathrm{m}$ and $0.05 \mu \mathrm{m}$, respectively. Reconstructed TVOIs were cylindrical: $0.7 \mu \mathrm{m}$ resolution (diameter $716 \mu \mathrm{m}$; height $358 \mu \mathrm{m}$ ) and $0.05 \mu \mathrm{m}$ resolution (diameter $100 \mu \mathrm{m}$; height $100 \mu \mathrm{m}$ ). For the $0.7 \mu \mathrm{m}$ resolution, scan a was located in the notched edge, where the sample net section diameter was the smallest ${ }^{1}$. Scans $\mathbf{b}, \mathbf{c}$ and $\mathbf{d}$ were located successively from scan $\mathbf{a}$, in line with the longitudinal axis. For the $0.05 \mu \mathrm{m}$ resolution, scan $\mathbf{A}$ was located in the centre of the notched section; whereas, scans $\mathbf{B}$ and $\mathbf{C}$ were shifted along the longitudinal axis of the sample by 1.4 and $1.6 \mathrm{~mm}$, respectively.

Tomographic volumes are 3D gray-level numerical objects. For a 8-bits volume, each voxel is characterized by a gray-level between 0 and 255, respectively black and white; accordingly, an image is characterized by its own graylevel histogram containing some artefacts and typically non uniform brightness. Cartography of the reconstructed longitudinal views of the $0.7 \mu \mathrm{m}$ resolution scans, from a down to d, are shown in Figure 4. Variations in gray-level are associated with variations in the bulk density traversed by the X-rays beam. Voids are reasonably well-defined

\footnotetext{
${ }^{1}$ In all that follows, bold lowercase and capital letters are used respectively for identifying low and high resolution TVOIs.
} 


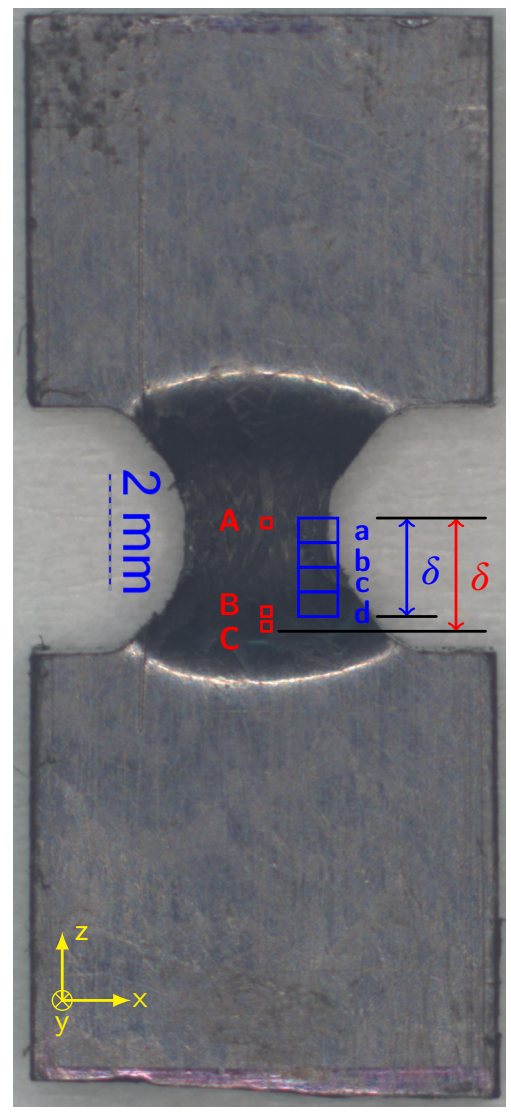

a)

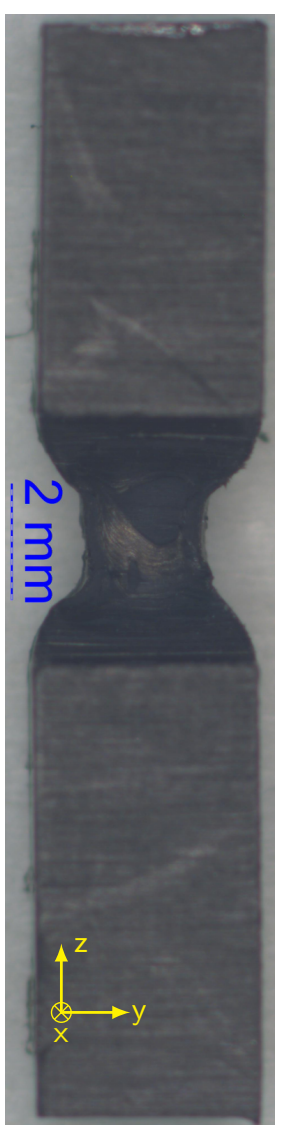

b)

Figure 3: Details of the notched zone of the studied sample and definition of the Tomographic Volume of Interest (TVOI): a) Width view: blue rectangle box $=$ TVOI for ID19 with $0.7 \mu \mathrm{m}$ resolution (TVOI diameter $=716 \mu \mathrm{m}$; height $=358 \mu \mathrm{m}$ ); red square box $=$ TVOI for ID22 with $0.05 \mu \mathrm{m}$ resolution $($ TVOI diameter $=100 \mu \mathrm{m}$; height $=100 \mu \mathrm{m}$ ); b) Thickness view.

in black whereas HDPE bulk appears in gray. White features are associated with the phase contrast of the void-bulk interface. Qualitative analysis of dimension, morphology and spatial distribution of cavities are then allowed.

As detailed in Figure 4, the deformed neck root is evidenced at the top right, from scan a down to $\mathbf{b}$, whereas the sample centre (mid-width) is located to the left (top white arrow). A heterogeneous population of cavities inside the matrix was observed; furthermore, some elongated cavities showing bright full circles inside were identified. Bright circles are rigid particles of unknown nature from which voids nucleated by debonding from the matrix-surface interface. In scans $\mathbf{a}$ and $\mathbf{b}$, elongated cavities are rather vertical (loading direction) whereas in scan $\mathbf{c}$ (right hand) the void is clearly tilted relative to the loading direction following the external surface inclination. A round void, without rigid particle inside, with a larger diameter than that of nucleated voids near the surface was identified in scan d (bottom left). This void nucleation was not observed in previous research on PA6 [15, 44]. Additionally, void patterns, similar to polar fans, with very-thin bright inter-void matter can be observed in the left region of all data sets. The polar fans display both a larger diameter and height in the central region. In line with the neck surface, polar fans exhibited inclination near the deformed neck root. However, on account of the low $0.7 \mu \mathrm{m}$ resolution to highlight effectively these polar-fan like objects in HDPE, a higher resolution is needed. Besides, higher resolution scans could allow quantification of the void characteristic dimensions; accordingly, a 3D image treatment is required.

Using two different procedures, the quantitative image analysis was performed. The reconstructed images were first analysed in real intensity by image segmentation. Then, through 2D process Fast Fourier Transforms (FFT), the intensity maps in the reciprocal space were studied. 


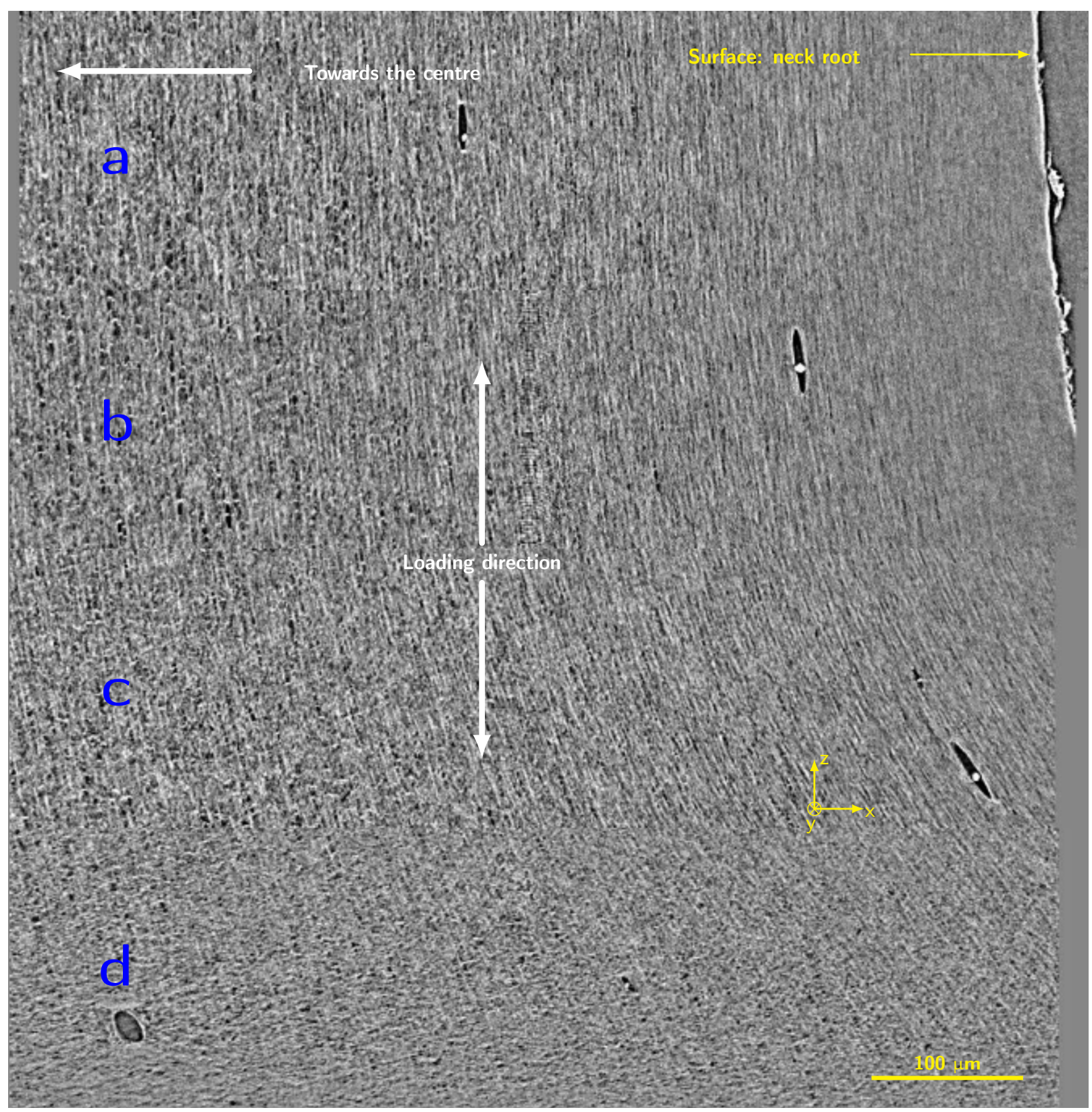

Figure 4: Longitudinal tomographic scans $1 \mathrm{px}=0.7 \mu \mathrm{m}$, TVOI $=1024 \times 1024 \times 512 \mathrm{px}$

\subsection{D imaging treatment \\ 3.4.1. Image segmentation}

A 3D image segmentation routine based on grey-level thresholding ${ }^{2}$ was used. As illustrated by Figure 5.a, for a $0.7 \mu \mathrm{m}$ resolution slice, different threshold values will return different image segmentations. The selection of the threshold is a suggestive operation since it demands the interpretation of the user. In Figure 5.a thresholding results are shown with a difference, between thresholding values, smaller than $2 \%$. After the image binarization, cavities are represented in black isolated from the bulk matrix in white; then, the number of cavities in each slice and their size can be studied. Moreover, labelling of each void allows to retrieve detailed information such as their coordinates,

${ }^{2} \mathrm{~A}$ threshold value allows to binarize an image dissociating cavities from the bulk 


\section{SEGMENTATION}

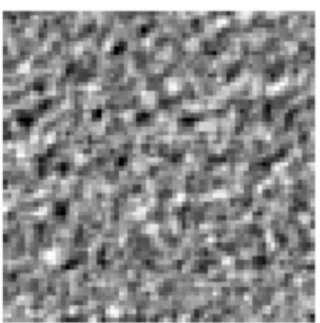

Original view

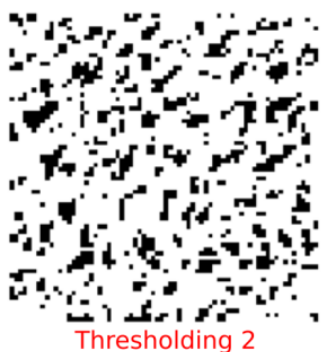

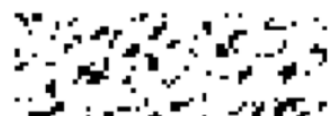

i

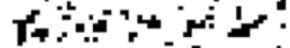

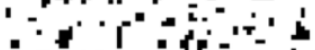

$\therefore$ т

Thresholding 1

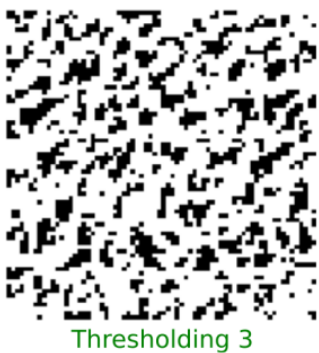

a)
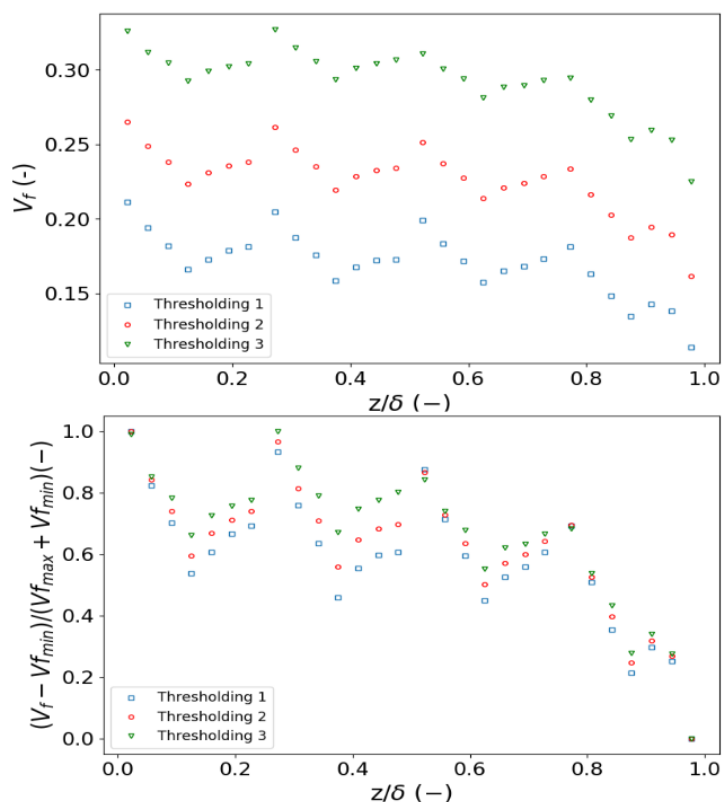

b)

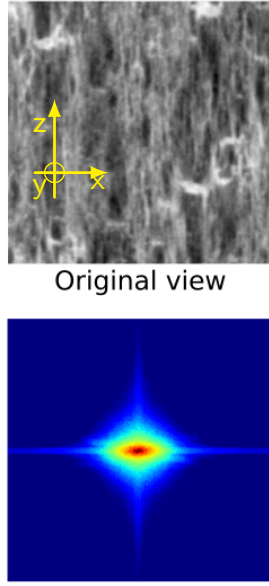

FFT

c)

FAST FOURIER TRANSFORM

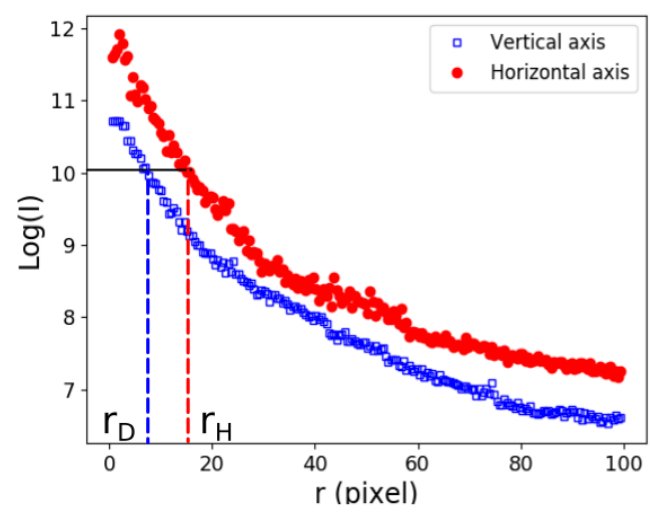

d)

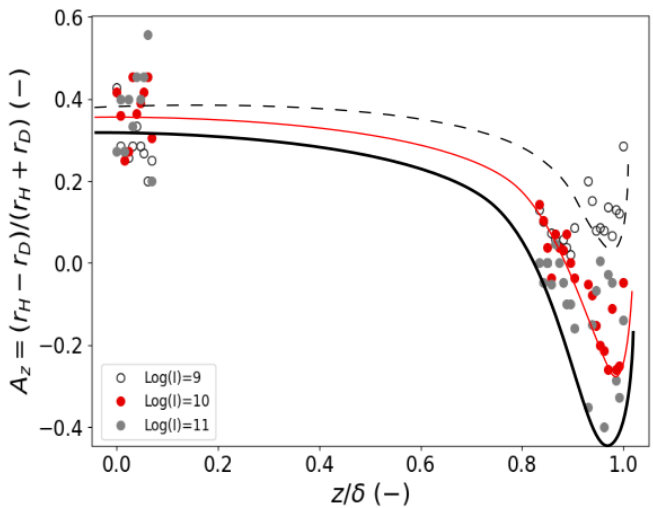

e)

Figure 5: 3D imaging treatment. Image segmentation: a) Qualitative, and b) Quantitative thresholding level effect (total and normalized void volume fraction). FFT analysis: c) Original image and reciprocal space image; d) Intensity (in log scale) versus reciprocal space distance curves: average height $r_{H}$, and diameter $r_{D}$; e) Axial anisotropy index evolution for different FFT intensity values.

characteristic dimensions, volume, and morphology.

To further analyze the data sets, Statistical Volumes-Of-Interest (SVOI) of about $50 \times 50 \times 50 \mu \mathrm{m}^{3}$ and $10 \times 10 \times 10$ $\mu \mathrm{m}^{3}$ with a resolution of $0.7 \mu \mathrm{m}[45,46]$ and $0.05 \mu \mathrm{m}$, respectively, were introduced. SVOIs with a $0.7 \mu \mathrm{m}$ resolution were cut-out in sequence, from a to $\mathbf{d}$ (see Figure 2), along the loading axis on the bulk-side of the TVOI. On the other hand, SVOIs with a $0.05 \mu \mathrm{m}$ resolution were cut-out in sequence, from $\mathbf{A}$ to $\mathbf{C}$ (see Figure 2), along the revolution axis on the TVOI. Finally, for each SVOI, the aforementioned void volume fraction $V_{f}$, the height $h$ and the diameter $d$ of each void was quantified using the python-based package Pymicro [21].

In Figure 5.b, the evolution of $V_{f}$ along the longitudinal axis for three different thresholding values is initially 
illustrated (top right). A significant difference, independently on the SVOI position along the longitudinal axis, was clearly found. Therefore, to better analyse the gradient trend of $V_{f}$, the normalized evolution of the void volume fraction has been defined as

$$
\frac{V_{f}-V_{f_{\min }}}{V_{f_{\max }}+V_{f_{\min }}}
$$

where $V_{f_{\min }}$ and $V_{f_{\max }}$ are respectively the corresponding minimum and maximum void volume fractions. By using this variable, (second, from top right) a similar trend was observed independently on the threshold value.

In the present study, using a segmentation threshold equals to 90 (-), Thresholding 2 in Figures 5.a and 5.b, independently on the TVOI resolution level, all SVOIs were treated. For each SVOI, the space coordinates, the height $h$ and the diameter $d$ of each individual void was measured. Thereafter, the normalized void volume fraction, then the axial anisotropy index were calculated. The normalized void volume fraction was estimated by Eq. 1. The axial anisotropy index $A_{Z}$, i.e. the axial evolution of the void shape characterized by the relation between the void height and diameter, was calculated as follows:

$$
A_{Z}=\frac{h-d}{h+d}
$$

\subsubsection{FFT analysis}

The FFT technique consists of analysing the gray-level discrete function of a $2 \mathrm{D}$ image in the frequency representation, i.e. in the reciprocal space. The amplitude module of the Fourier transform, called spectrum and corresponding to the square root of the sum of the squares of both the imaginary and real parts, contains information such as the periodicity of the image, the patterns and their orientations. In an image, the frequency represents the change of intensity of the image, e.g. the high frequencies represent the contours, details or noise.

Using an in-house python based FFT routine implemented in Pymicro [21], the same SVOIs, used in the 3D image segmentation study, were analysed in order to obtain quantitative data about the microstructure objects morphology. The three volume axis were considered. For each axis, the averaged FFT module from about 70 and 200 images for a resolution of $0.7 \mu \mathrm{m}$ and $0.05 \mu \mathrm{m}$, respectively, was calculated. As an example, the logarithmic-scale map in the $x-z$ plane in the reciprocal space from the FFT routine, for a $0.05 \mu \mathrm{m}$ resolution SVOI from the A TVOI, is shown in Figure 5.c The FFT image is centred, i.e. a null frequency is placed in the centre whereas high frequencies are situated in the border of the image. In Figure 5.d, the corresponding evolution of the intensity profile as a function of the spatial frequency q (in pixel) is highlighted for two orthogonal axis: horizontal (in red), and vertical axis (in blue). A similar method, on image stacks with a spatial resolution slightly inferior to $1 \mu \mathrm{m}$, was used by Blaise et al. [22] to obtain quantitative information about the average size of the objects exhibiting an absorption contrast with respect to an HDPE matrix. The anisotropy change of the microstructure upon stretching was clearly shown.

Contrary to Blaise et al. [22], no peaks, assigned to the presence of short-range correlations in the microstructure, were observed in the intensity profile. To overcome this difficulty, a different strategy is then proposed. A fixed FFT intensity was used to estimate the corresponding average values of the feature dimensions $r_{i}$ in the microstructure. The feature height $r_{H}$ and diameter $r_{D}$ were estimated respectively from the intersection of the intensity with the horizontal and vertical intensity profiles, as shown in Figure 5.d. In order to verify the sensitivity of the intensity parameter over the quantitative results, the effect of the FFT intensity on the anisotropy index $A_{z}$ was studied. The anisotropy index, from the FFT protocol, was defined by

$$
A_{Z}=\frac{r_{H}-r_{D}}{r_{H}+r_{D}}
$$

The anisotropy index along the longitudinal axis from the $0.05 \mu \mathrm{m}$ resolution for three intensity values is shown in Figure 5.e. Although a slight difference was found, a similar trend was observed independently on the intensity value.

The average logarithmic-scale map (2D-FFT map), in the reciprocal space, in the $x-z$ plane, i.e. the side-view plane, and in the $x-y$ plane, i.e. the top-view plane, for each SVOI was extracted, as can be seen in Figure 13. Therefore, the corresponding evolution of the intensity profile as a function of the spatial frequency for two orthogonal axis, i.e. the horizontal axis (respectively $z$ and $y$ for the side-view and the top-view plane) and the vertical axis ( $x$ for the side-view and the top-view plane), was plotted. The average feature height $r_{H}$ and diameter $r_{D}$ were estimated respectively from the projection of the intersection of an intensity equals to $\log (I)=10(-)$ with the horizontal and 
vertical profiles from the side-view map (e.g. Figures 5.d and 5.e). The evolution of the average feature diameter $r_{D}^{\prime}$ from the $y$ direction is not discussed as no significant difference concerning the $x$ direction was observed, i.e. $r_{D} / r_{D}^{\prime} \leq 1.01$. Afterwards, the axial anisotropy index was calculated by Eq. 3 .

In order to compare the axial anisotropy index from the image segmentation method and the FFT analysis, a normalized axial anisotropy index was calculated from:

$$
\frac{A_{Z}}{A_{Z(\max )}}
$$

where $A_{Z(\max )}$ is the maximum positive axial anisotropy index, i.e. $r_{H} \geq r_{D}$.

Besides, in order to study the microstructure evolution along the longitudinal axis in HDPE, the axial coordinate $z$ of the SVOI in the deformed state was normalized by the local opening displacement $\delta$ (see Figure 3.a), so that $z / \delta=0$ and $z / \delta=1$ correspond respectively to the centre and the neck shoulder. The local opening displacement is defined as the distance between the centre of the sample and the position of the corresponding furthest TVOI, equals to 1432 $\mu \mathrm{m}$ and to $1700 \mu \mathrm{m}$, the distance between a to $\mathbf{d}$ and between $\mathbf{A}$ to $\mathbf{C}$, respectively at the $0.7 \mu \mathrm{m}$ and the $0.05 \mu \mathrm{m}$ resolution.

\section{Results and discussion}

\subsection{Qualitative study of the microstructure evolution in PA6 and HDPE}

In this section, a qualitative study of the microstructure evolution along the longitudinal axis, i.e. the extended neck region and both the beginning and the end of the neck shoulder, in a PolyAmide 6 and HDPE both at low resolution, and HDPE at high resolution is discussed.

Figures 6 to 11 display 2D tomography images of a thermoplastic PolyAmide 6, from previous works [15, 44] on notched round bar samples during interrupted tensile tests, at a $0.7 \mu \mathrm{m}$ resolution, and of HDPE at the $0.7 \mu \mathrm{m}$ and 0.05 $\mu \mathrm{m}$ resolution (PA6, $\mathrm{HDPE}_{0.7}$, and $\mathrm{HDPE}_{0.05}$, respectively). Slice views of PA6, $\mathrm{HDPE}_{0.7}$, and $\mathrm{HDPE}_{0.05}$ are situated respectively in the top left (bold-line boxed image), top right and bottom (magnified). Cavities are in black, polymer matrix is in grey and intervoid walls, and inclusions, are in brighter grey, or even in white. Slice views suggest the presence of two populations of cavities:

- Nucleated from inclusions, e.g. intersection of yellow lines in Figures 6 to 11, where the inclusions are noticeably highlighted in bright white, and

- without inclusions: not well resolved (smaller size). Presumably, void nucleation within equatorial and polar fans due to the spherulitic structure [16, 17].

\subsubsection{In the plane of the extended necked region $(A, a)$}

In Figure 6 and Figure 7, respectively side and top views, the distribution and morphology of cavities in the plane of the neck region are studied. The slice views of PA6 correspond to scans, from the central part of the deformed samples, at the end of the plateau, i.e. at the maximum extension of the necked region. The slice views of $\mathrm{HDPE}_{0.7}$ and $\mathrm{HDPE}_{0.05}$ correspond respectively to scans $\mathbf{a}$ and $\mathbf{A}$ in Figure 3. The samples surfaces are observed on the side and top views of PA6, respectively Figures 6.a and 7.a, and $\mathrm{HDPE}_{0.7}$, respectively Figures 6.b and 7.b. Towards the neck root, the distribution of cavities appears to be the same for the two materials; moreover, analogous phenomena, i.e. cavities arranged in columns, similar to polar fans [16], and orientated towards the loading axis ( $z$-axis) were observed. Contrary to previous results [14], no inclination of the polar fans were observed here. A significant reduction in void number and in void diameter, when approaching the neck root surface, is clearly shown for PA6. It appears that HDPE 0.7 follows a similar trend; however, it is not very clear since phenomena seems to occur at a lower scale. Besides, no visible cavitation was evidenced at the surface of the samples. An increasing gradient in white-spot number towards the centre of the sample, related with the void-bulk interface phase contrast, is observed. A similar behaviour is clearly noticed in the sample surface where a bright (white) curve, parallel to the surface, is shown.

Using a higher resolution, no gradient in void number nor void diameter was observed along the $x$-axis on the side and top views of $\mathrm{HDPE}_{0.05}$, respectively Figures 6.c and 7.c. In line with Figure 3, the slice views of $\mathrm{HDPE}_{0.05}$ corresponds to the central zone of the sample then, according to the gradient evolution of cavities morphology in $\mathrm{PAC}$ and $\mathrm{HDPF}_{0.7}$, no significant evolution was expected Cavities arranged in columns, identical to PA6, were clearly 

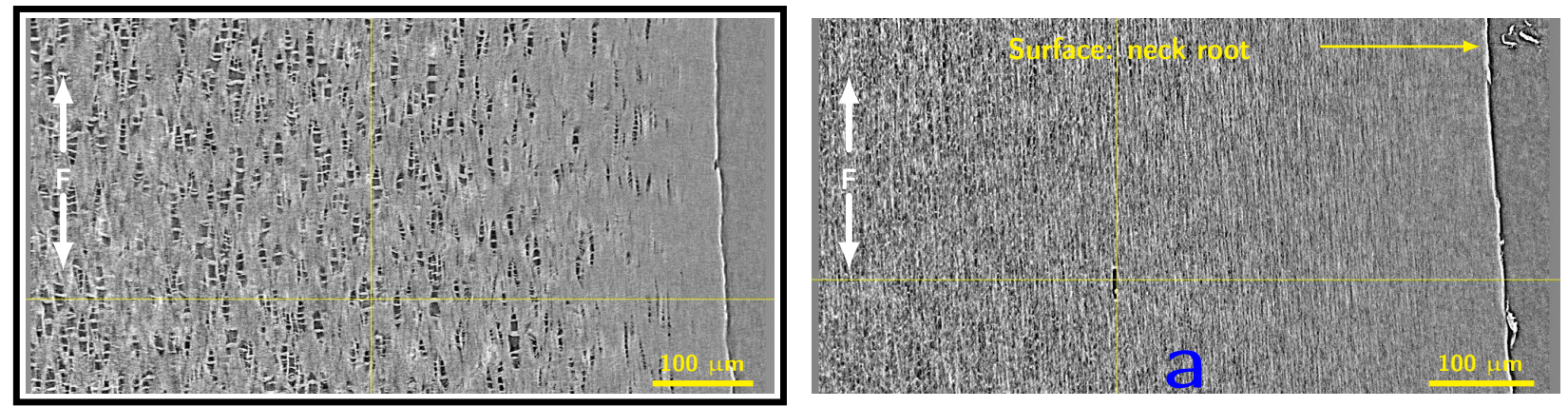

a)

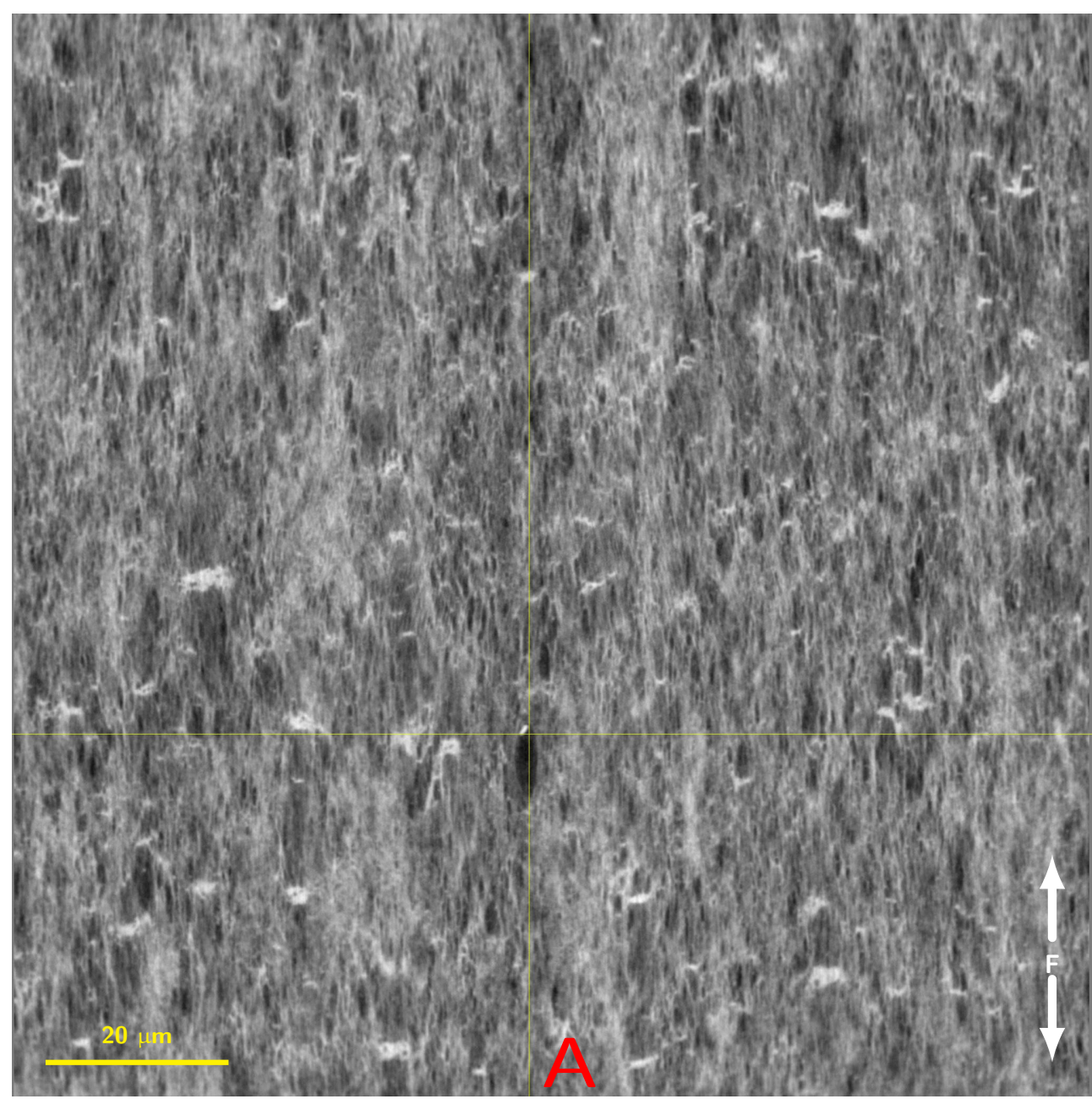

b)

c)

Figure 6: Comparison of tomography images at the extended necked region of the inspected samples (side views): a) reference PA6 $[15,44]$ with $1 \mathrm{px} \sim 0.7 \mu \mathrm{m}$; b) HDPE with the same resolution as reference PA6 $1 \mathrm{px} \sim 0.7 \mu \mathrm{m} ; \mathrm{c})$ HDPE with high resolution $1 \mathrm{px} \sim 0.05 \mu \mathrm{m}$

highlighted; moreover, horizontal fibrils, in brighter grey, corroborate a similar cavitation phenomena than in PA6 [44]. Moreover, observations of the scans on the top view, see Figure 7, evidence a circular shape of the cavities in the perpendicular plane, it can therefore be inferred that cavities have a prolate spheroidal geometry with an height greater than the diameter.

\subsubsection{In a plane at the beginning of the neck shoulder $(B, b, c)$}



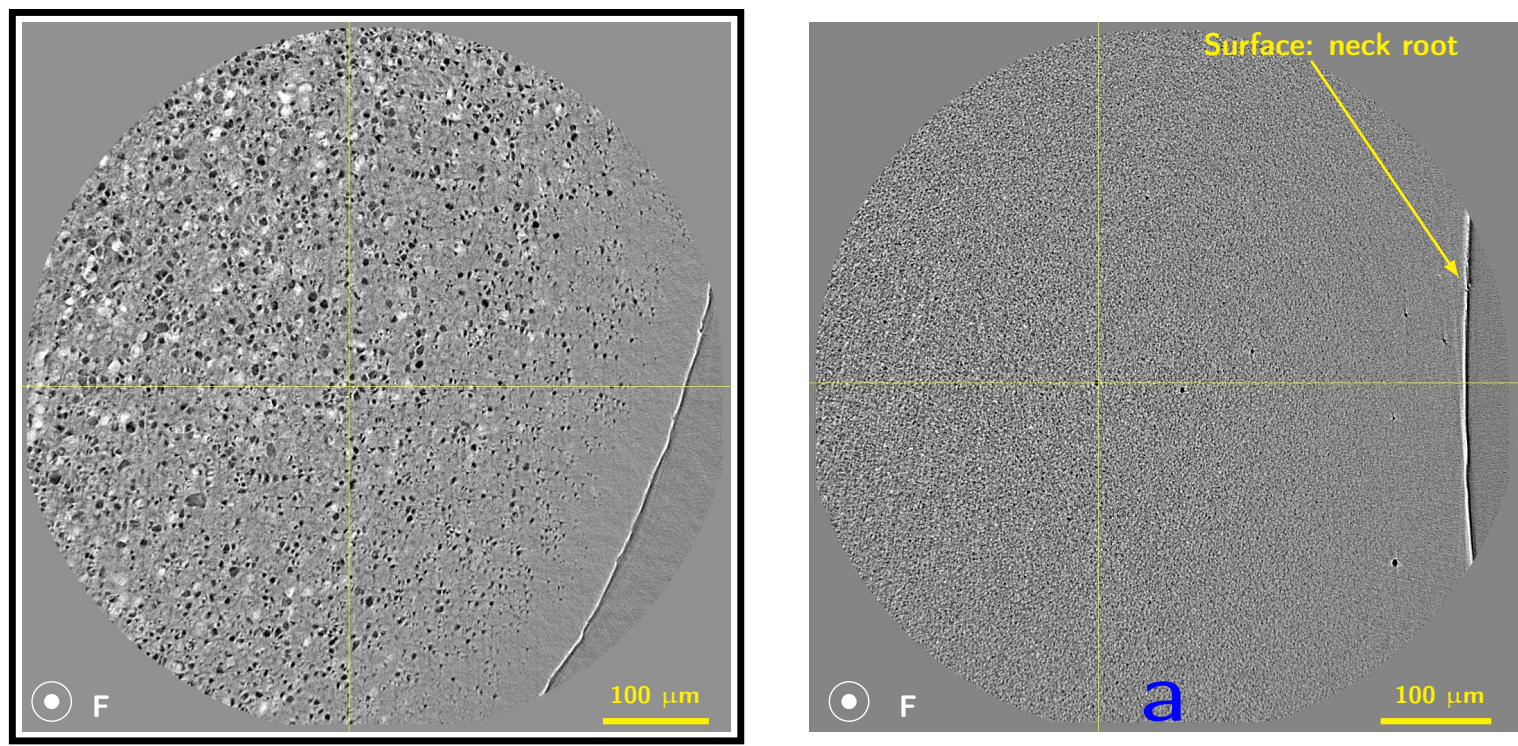

a)

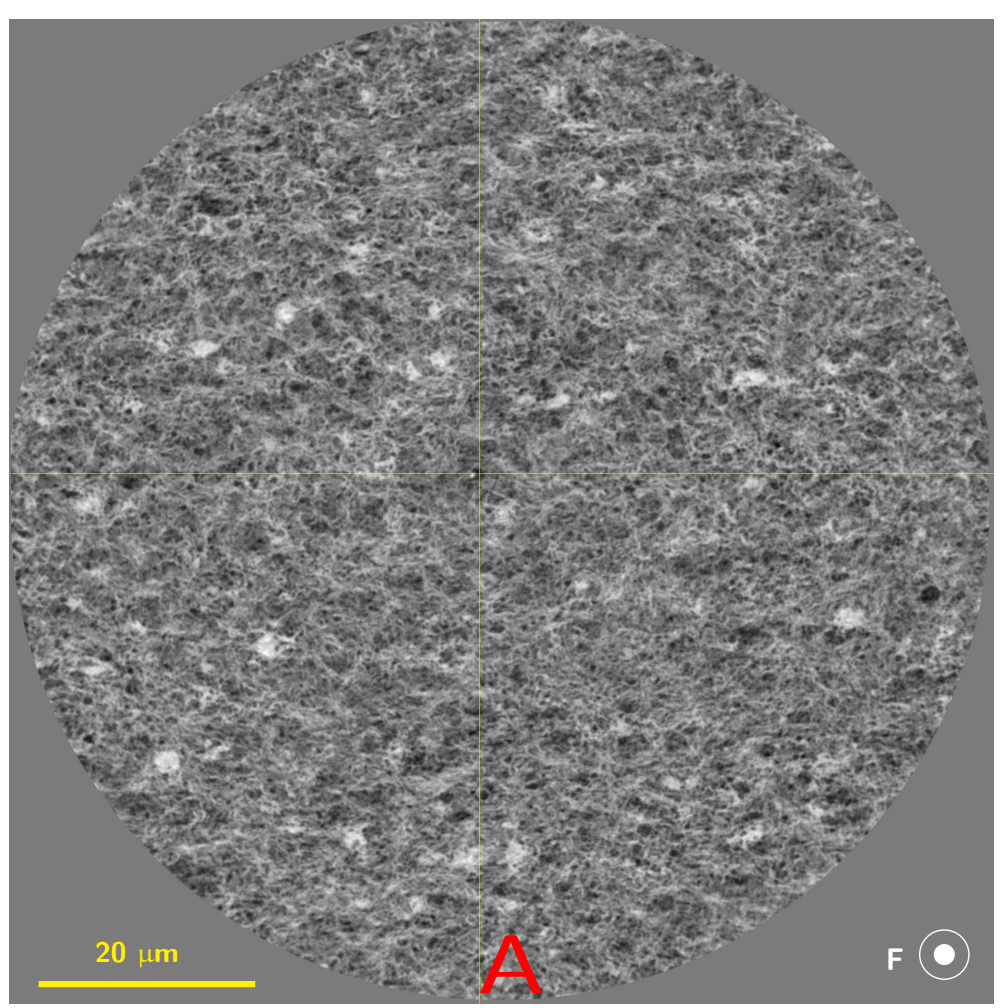

b)

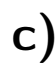

Figure 7: Comparison of tomography images at the extended necked region of the inspected samples (top views): a) reference PA6 $[15,44]$ with $1 \mathrm{px} \sim 0.7 \mu \mathrm{m}$; b) HDPE with the same resolution as reference PA6 $1 \mathrm{px} \sim 0.7 \mu \mathrm{m}$; c) HDPE 5.awith high resolution $1 \mathrm{px} \sim 0.05 \mu \mathrm{m}$

The effect of the neck geometry on the voids morphology evolution is studied in Figure 8 and Figure 9, respectively the side and top views. The slice views of PA6 correspond to scans, from the central part of the deformed samples, at the end of the stress-softening, so that the renecked shoulder could be observed. The slice views of $\mathrm{HDPE}_{0.7}$ correspond to scan $\mathbf{c}$ in Figure 3, i.e. right border points out towards the neck surface, whereas slice views of $\mathrm{HDPE}_{0.05}$ correspond to scan $\mathbf{B}$ in Figure 3. Similar than on the plane of the extended necked region, a reduction in void diameter 

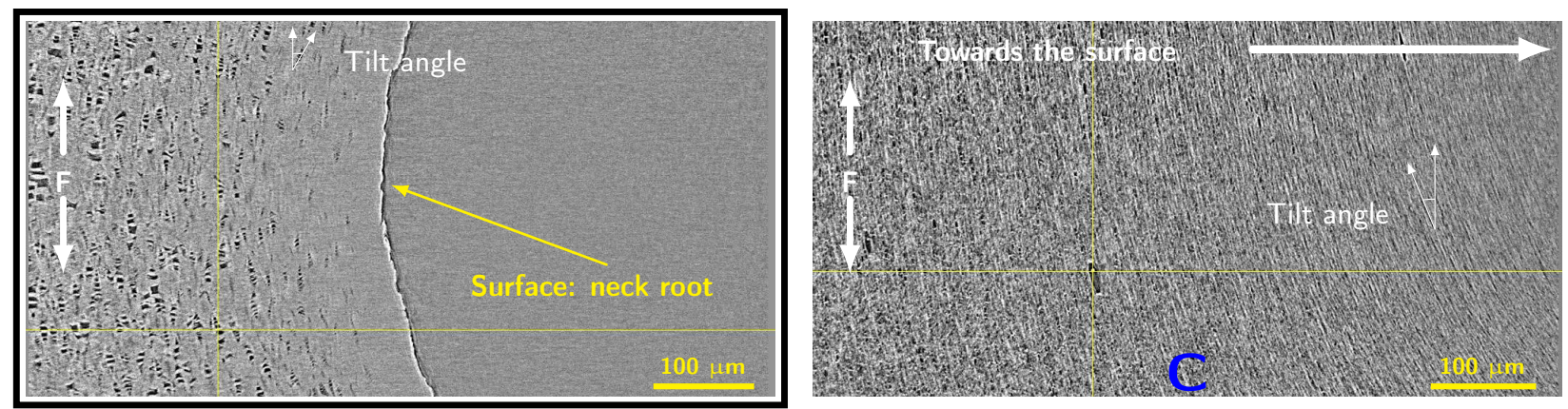

a)

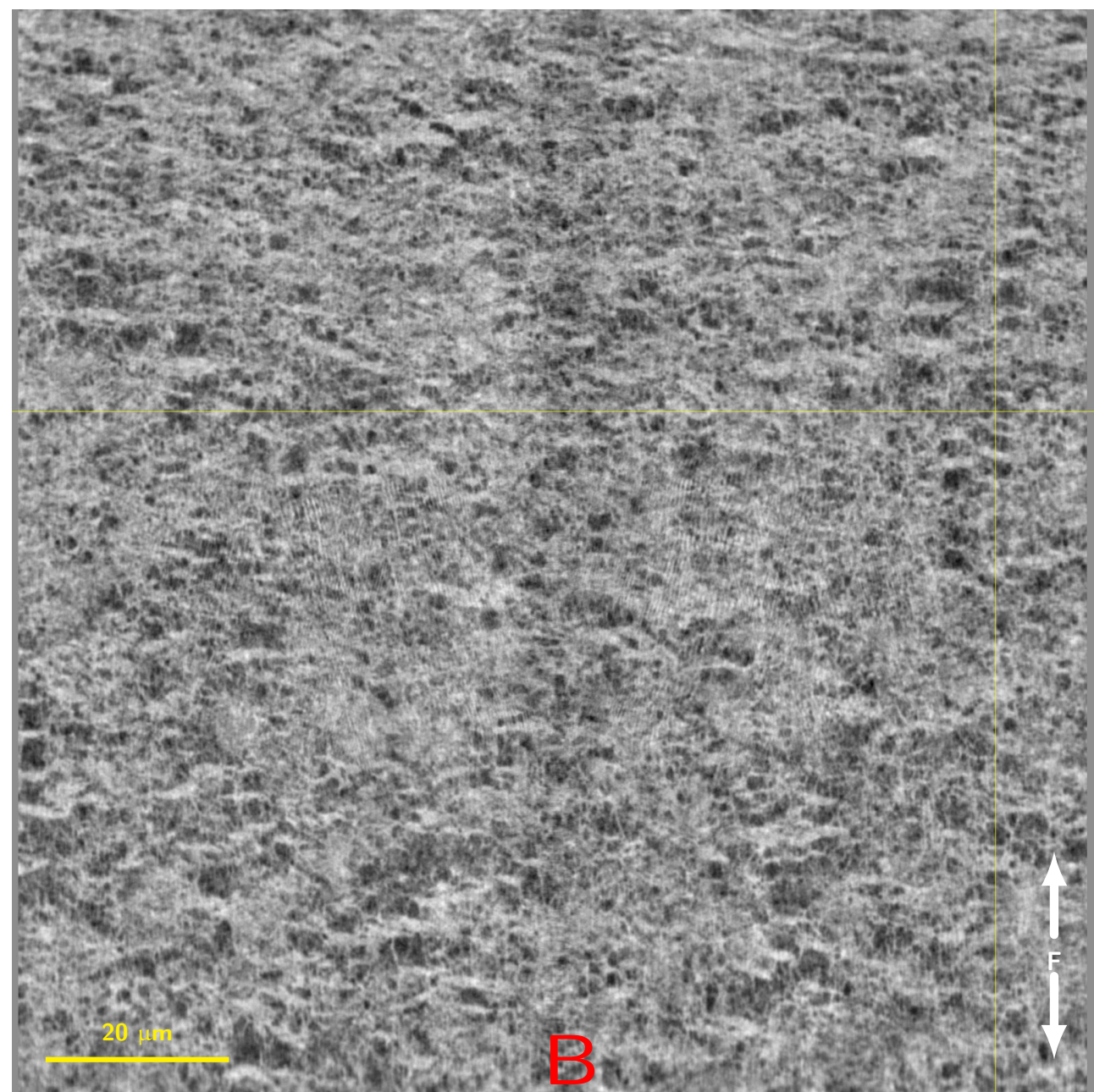

b)

c)

Figure 8: Comparison of tomography images at the beginning of the neck shoulder of the inspected samples (side views): a) reference PA6 $[15,44]$ with $1 \mathrm{px} \sim 0.7 \mu \mathrm{m}$; b) HDPE with the same resolution as reference PA6 $1 \mathrm{px} \sim 0.7 \mu \mathrm{m}$; c) HDPE with high resolution $1 \mathrm{px} \sim 0.05 \mu \mathrm{m}$

when approaching the neck surface is clearly highlighted in PA6. It seems that $\mathrm{HDPE}_{0.7}$ follows a similar trend but, regrettably, it is not very clear since phenomena occur at a lower scale. Cavities are arranged in polar fans, as illustrated in Figure 8.a; however, contrary to observations on the extended necked region, they are dramatically orientated according to the neck surface, i.e. near the neck surface voids axis follows the surface. The maximum in-plane tilt angle, the angle between the loading axis and the global orientation of the polar fans, i.e. the clusters of voids aligned in columns, was estimated at $6^{\circ}$ and $7^{\circ}$ for the PA 6 and the $H D P E_{0.7}$, respectively Due to low resolution on $H_{D P E} .7$ 

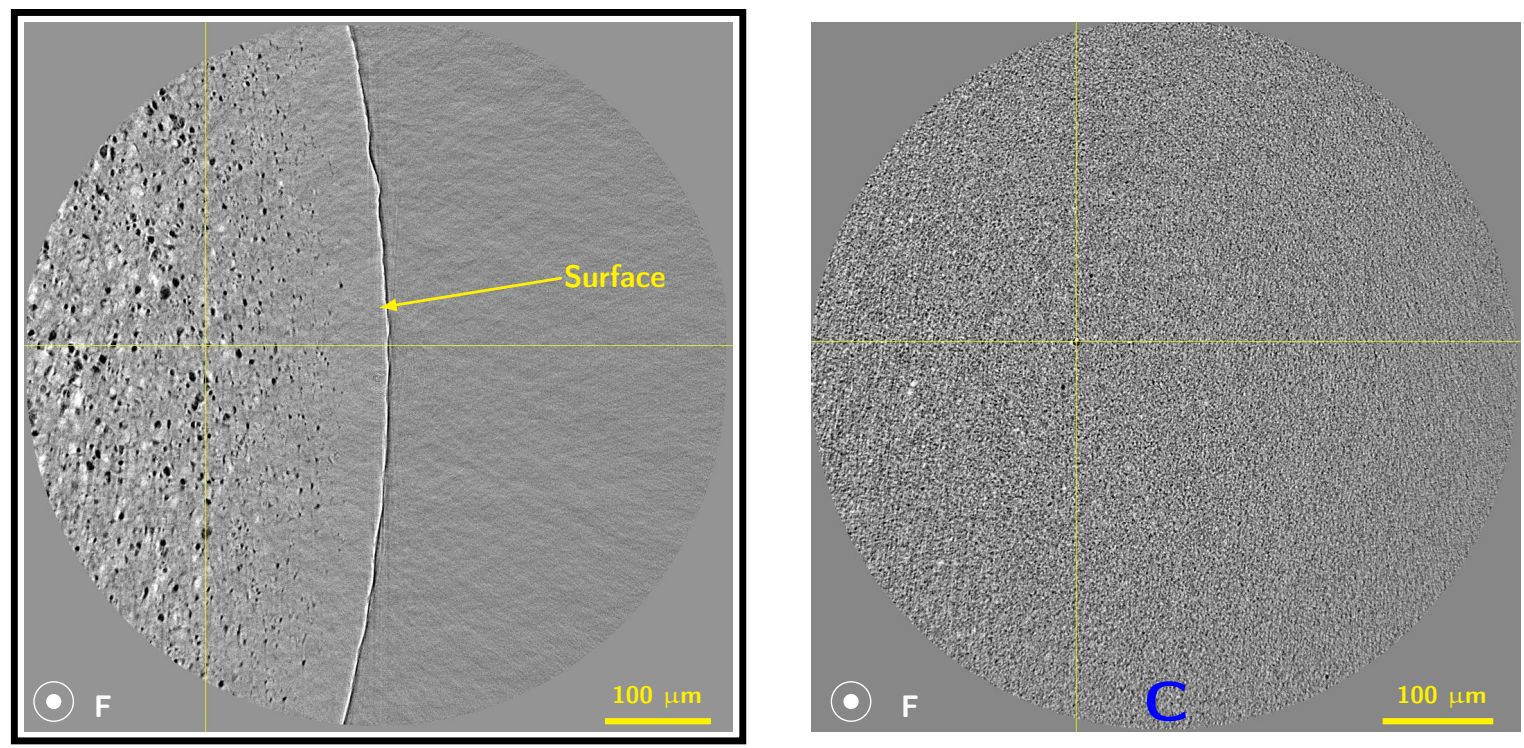

a)

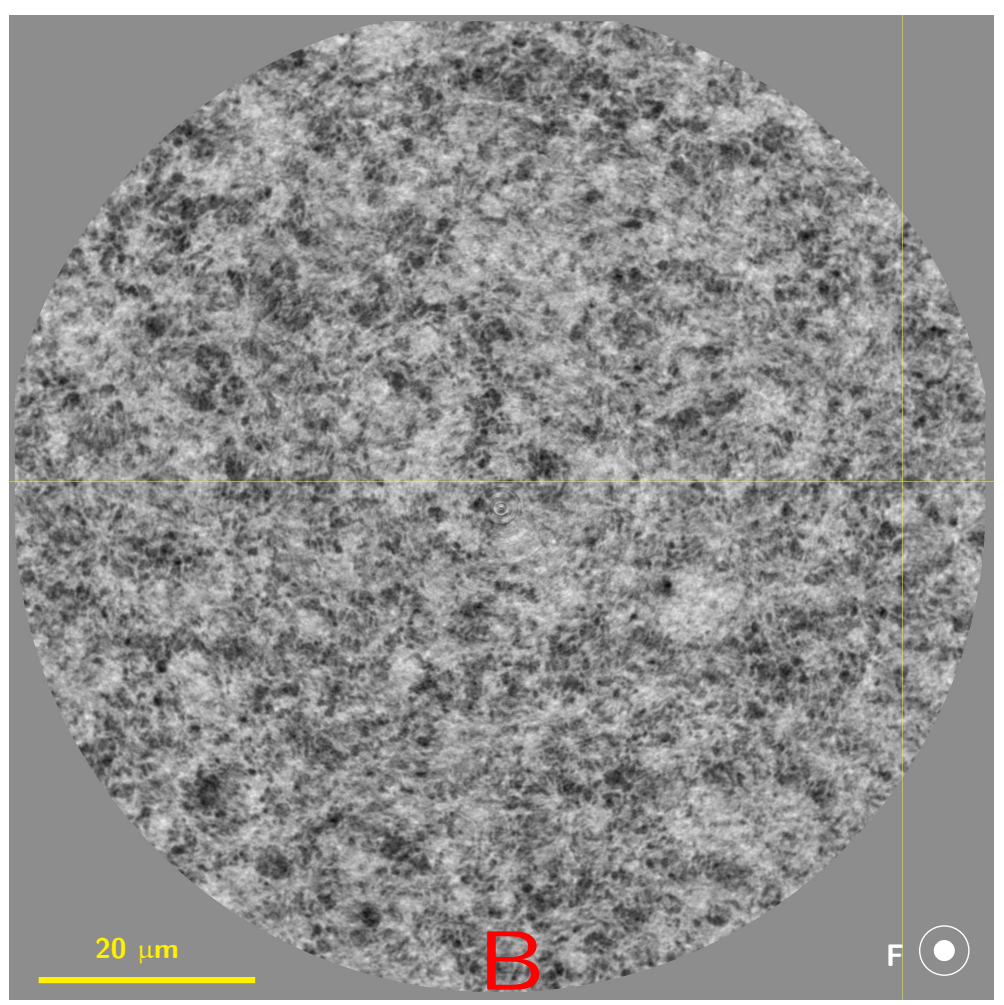

b)

c)

Figure 9: Comparison of tomography images at the beginning of the neck shoulder of the inspected samples (top views): a) reference PA6 $[15,44]$ with $1 \mathrm{px} \sim 0.7 \mu \mathrm{m}$; b) HDPE with the same resolution as reference PA6 $1 \mathrm{px} \sim 0.7 \mu \mathrm{m}$; c) HDPE with high resolution $1 \mathrm{px} \sim 0.05 \mu \mathrm{m}$

the polar fans are scarcely identified.

Associated to a higher resolution than that of $\mathrm{HDPE}_{0.7}$, polar fans are clearly identified on $\mathrm{HDPE}_{0.05}$, see Figure 8.c. Contrary to observations in PA6 and $\mathrm{HDPE}_{0.7}$, polar fans were orientated along the loading axis. Besides, it may be reasonable to suppose that void morphology evolves from the centre to the neck shoulder along the loading axis ( $z$ axis). Comparing Figures 6 and 8, respectively slices at the extended necked region and at the beginning of the neck 

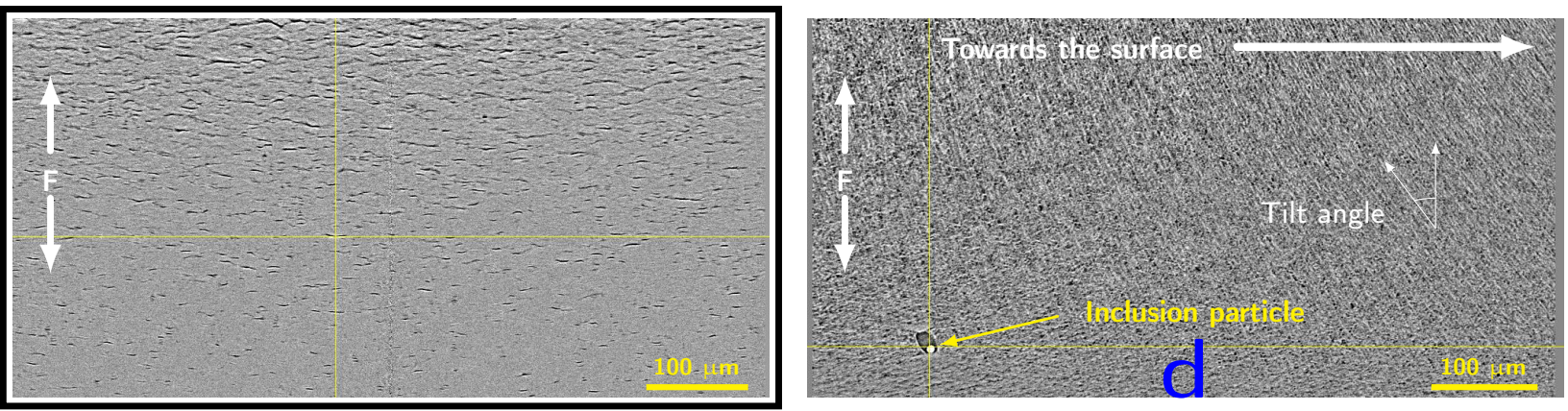

a)

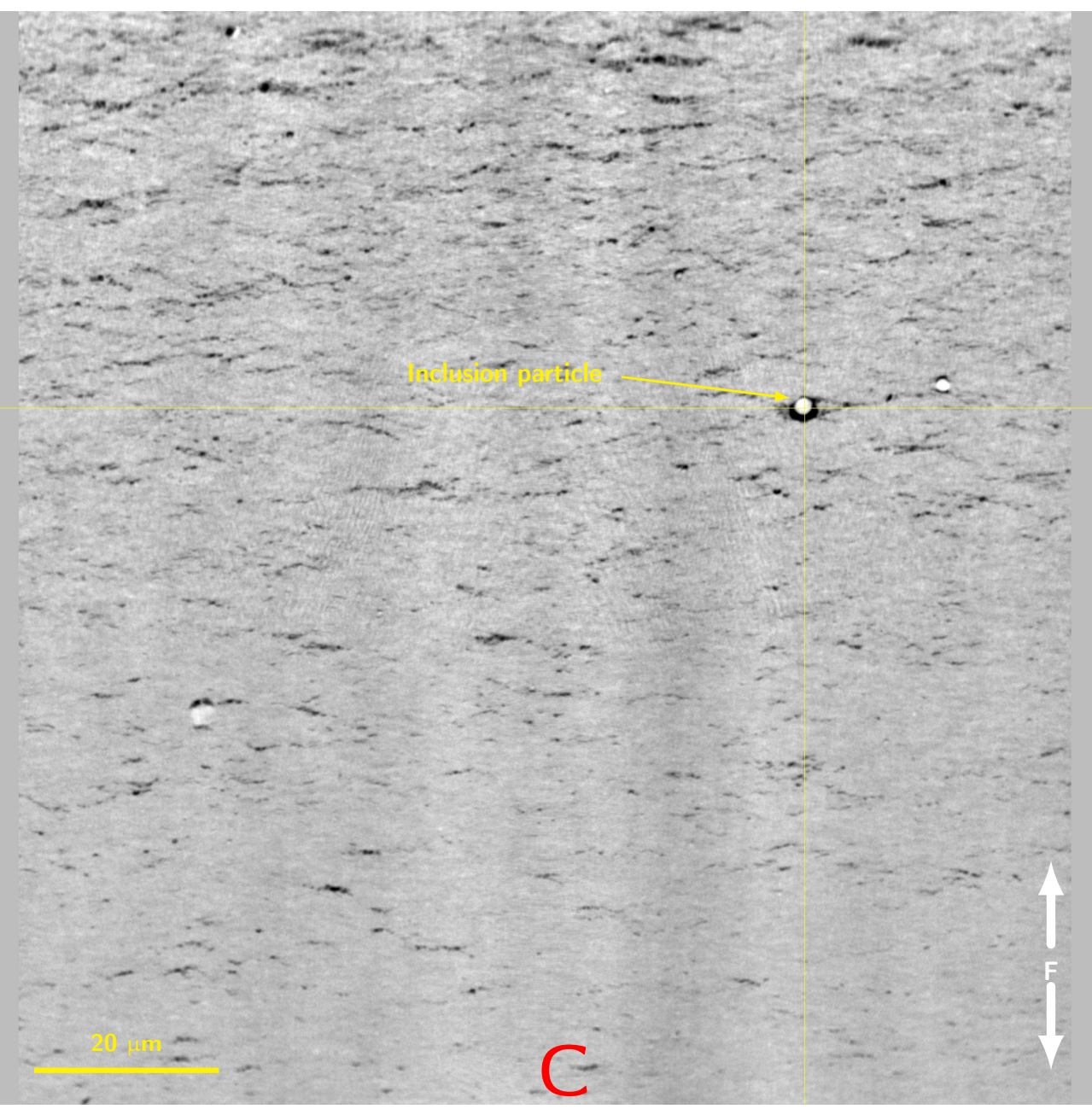

b)

c)

Figure 10: Comparison of tomography images at the end of the neck shoulder of the inspected samples (side views): a) reference PA6 $[15,44]$ with $1 \mathrm{px} \sim 0.7 \mu \mathrm{m}$; b) HDPE with the same resolution as reference PA6 $1 \mathrm{px} \sim 0.7 \mu \mathrm{m}$; c) HDPE with high resolution $1 \mathrm{px} \sim 0.05 \mu \mathrm{m}$

shoulder, a reduction of the void height was highlighted. No significant reduction of the diameter was observed, see Figures 7 and 9. Accounting for the circular shape of cavities in the top view, according to Figure 9, it can be then inferred that cavities are cylindrical, with an height equal to the diameter, or conical (end of the polar fans).

\subsubsection{In the plane of the end of the neck shoulder $(C, d)$}



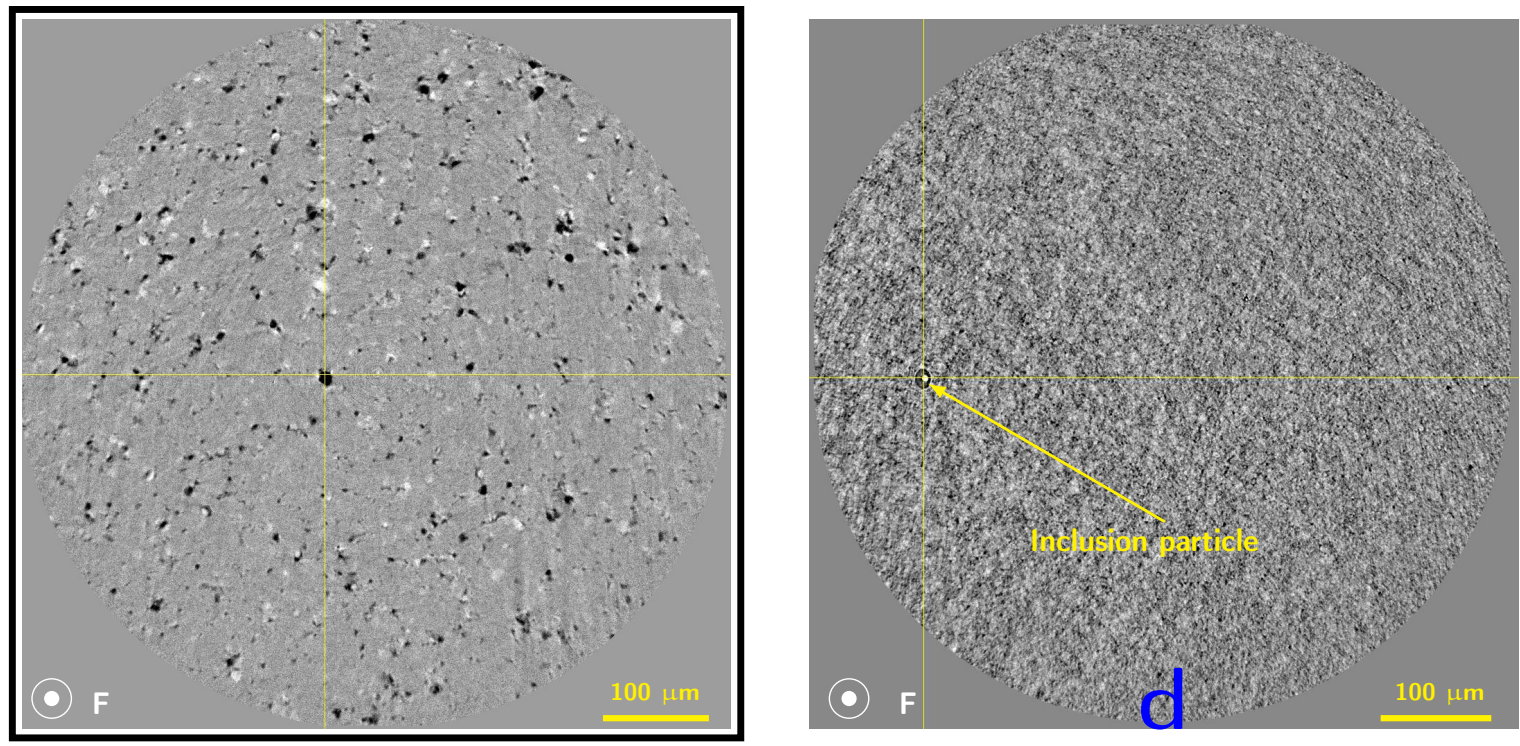

a)

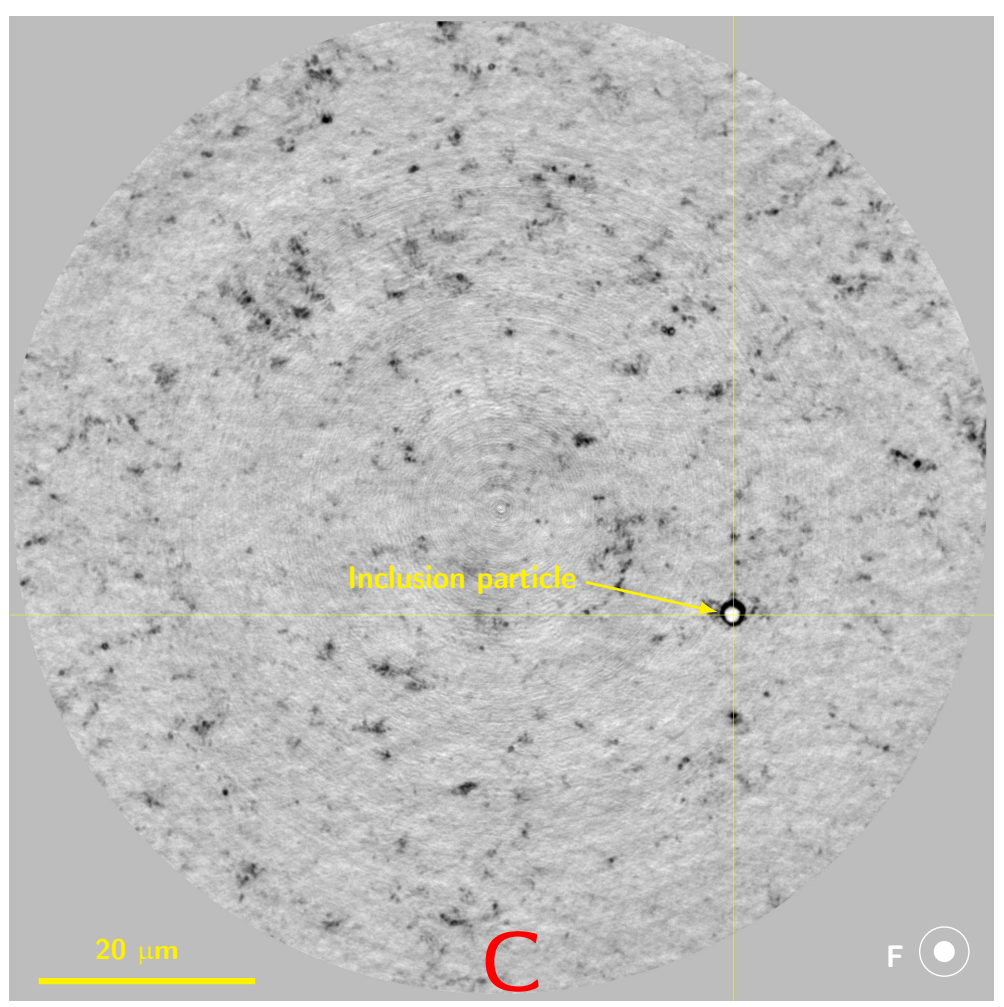

b)

\section{c)}

Figure 11: Comparison of tomography images at the end of the neck shoulder of the inspected samples (top views): a) reference PA6 $[15,44]$ with $1 \mathrm{px} \sim 0.7 \mu \mathrm{m}$; b) HDPE with the same resolution as reference PA6 $1 \mathrm{px} \sim 0.7 \mu \mathrm{m} ; \mathrm{c})$ HDPE with high resolution $1 \mathrm{px} \sim 0.05 \mu \mathrm{m}$

In Figure 10 and Figure 11, respectively side and top views, the distribution and morphology of cavities in the end of the neck shoulder is studied. The slice views of PA6 correspond to scans, from the central part of the deformed samples, at the maximum net stress. The slice views of $\mathrm{HDPE}_{0.7}$ and $\mathrm{HDPE}_{0.05}$ correspond respectively to scans $\mathbf{d}$ and $\mathbf{C}$ in Figure 3. Contrary to previous observations on PA6 and $\mathrm{HDPE}_{0.05}$, polar fans are not yet formed, respectively in Figures 10.a and 10.c; although, horizontal stripes were observed. Furthermore, a significant decrease of the stripe 
length and the stripe density along the loading axis when moving away from the centre, i.e. getting outside the neck, was observed. In fact, when the distance to the centre is large enough, cavities are very punctual. The same trends at different scales for both the PA6 and $\mathrm{HDPE}_{0.05}$, respectively with a resolution of $0.7 \mu \mathrm{m}$ and $0.05 \mu \mathrm{m}$, were highlighted. Besides, the presence of particle-nucleated voids in $\mathrm{HDPE}_{0.05}$, not observed in PA6, were identified. Additionnaly, thanks to a higher resolution, $\mathrm{HDPE}_{0.05}$ seems to evidence that the radial stripes are composed of horizontally aligned round nano-cavities in coalescence.

On the other hand, horizontal stripes in both the PA6 and the $\mathrm{HDPE}_{0.05}$ have a circular shape in the top view, see respectively Figures 11.a and 11.c. Therefore, the stripes can be seen as penny-shaped disks, i.e. oblate spheroidal geometry, with an height shorter than the diameter. In Figure 11.c, one round nucleated void from a rigid particle is highlighted. Moreover, compared with PA6 in Figure 11.a, coalescence in HDPE is not yet complete in all radial directions.

Apparently, no significant evolution in void number nor void diameter was observed in $\mathrm{HDPE}_{0.7}$, see Figures $10 . \mathrm{b}$ and 11.b. In a similar way than in the plane between the neck root and the neck shoulder, the polar fans in $\mathrm{HDPE}_{0.7}$ were orientated according to the neck surface. The maximum in-plane tilt angle was estimated at $13^{\circ}$.

The previous subsection was concerned with the qualitative study of the void morphology evolution in PA6 and HDPE, both at low resolution, and HDPE at high resolution. Following subsections will deal with a quantitative study of the void characteristics evolution in HDPE, at low and high resolution, along the longitudinal axis.

\subsection{Quantitative study of the microstructure evolution in HDPE}

By opposition to previous research on PA6 where radial TVOIs were studied allowing plots with respect to normalized radial coordinates, a quantitative study of the longitudinal microstructure evolution (i.e. cavities dimensions, void volume fraction and axial anisotropy index) on HDPE, both near the notch edge and centred on the longitudinal axis respectively at low and high resolution, is detailed. Two already discussed procedures were used: Image segmentation, and the FFT analysis.

From the following, the results from the $0.7 \mu \mathrm{m}$ resolution scans are systematically plotted in blue, whereas the results from the $0.05 \mu \mathrm{m}$ resolution scans are plotted in red.

\subsubsection{Comparative study of the cavities dimensions in HDPE}

Side views in Figure 12 show a significant decrease of the cavities height from the extended neck region to the end of the neck shoulder, from $\mathbf{a}$ down to $\mathbf{d}$ and from $\mathbf{A}$ down to $\mathbf{C}$ respectively at low and high resolution. Moreover, a slight increase of the cavities diameter is observed. Top-view segmented slices seems to evidence a reasonably circular shape of cavities. Consistent with previous conclusions, cavities evolve from a prolate to an oblate spheroidal geometry from the extended neck region to the end of the neck shoulder; furthermore, the side and top $\mathbf{B}$ slices suggest a spherical morphology transition in a plane at the beginning of the neck shoulder. Additionnaly, the results offer a brief idea of the evolution of the void volume fraction along the loading axis. In agreement with previous observations, it seems that void density decreases when getting outside the neck, independently on the position of the $z$-axis; although, bigger black spots, associated with a higher cavity diameter, seem to be situated near the shoulder. Subsequently, the void volume fraction appears to decrease but in a lower order than the void density.

In Figure 13, the average 2D-FFT maps, from the extended neck region to the end of the neck shoulder, from $\mathbf{a}$ down to $\mathbf{d}$ and from $\mathbf{A}$ down to $\mathbf{C}$ respectively at low and high resolution, are shown. In both cases, the sideview 2D-FFT maps were obtained from the slices taken perpendicularly to the loading axis whereas the top-view 2D-FFT maps were obtained from the slices taken parallel to the loading axis. The results highlight, independently on the reconstructed image resolution, a transition of the microstructure features from a prolate to an oblate spheroidal geometry. Concerning the morphology of the voids for a plane perpendicular to the loading axis, an isotropic pattern is shown, i.e. a circular shape is expected for the top view of the cavities, independently on the position of the void within the test sample. Furthermore, the $2 \mathrm{D}-\mathrm{FFT}_{0.05}$ map suggest a spherical morphology transition in a plane between the centre and the shoulder of the sample, see $\mathbf{B}$ in Figure 13. Besides, a higher gradient is observed for the 2D-FFT patterns with a higher resolution. 
Side views

a

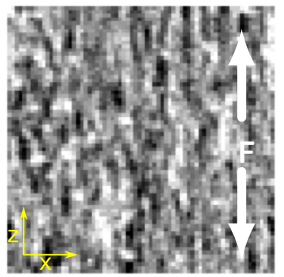

b
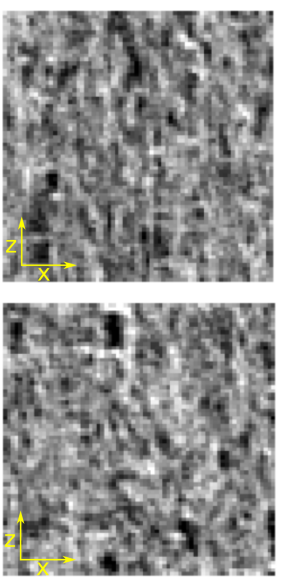

d

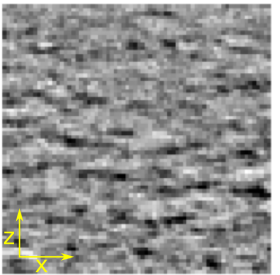

A
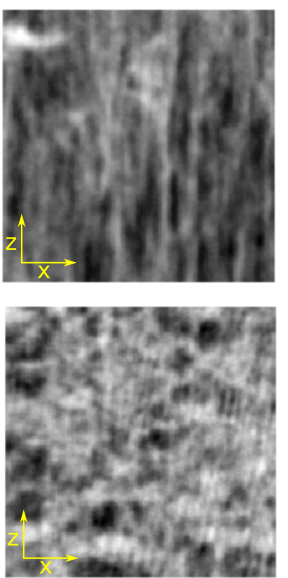

B
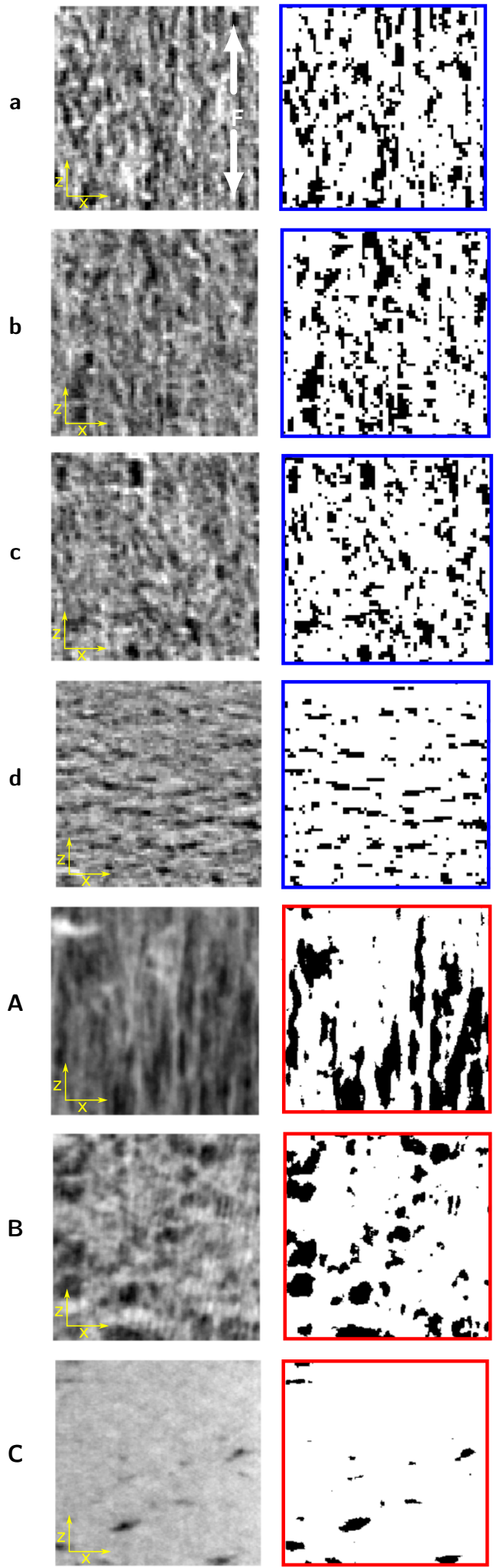

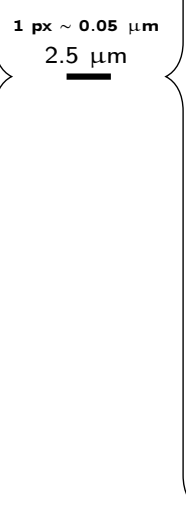

Top views
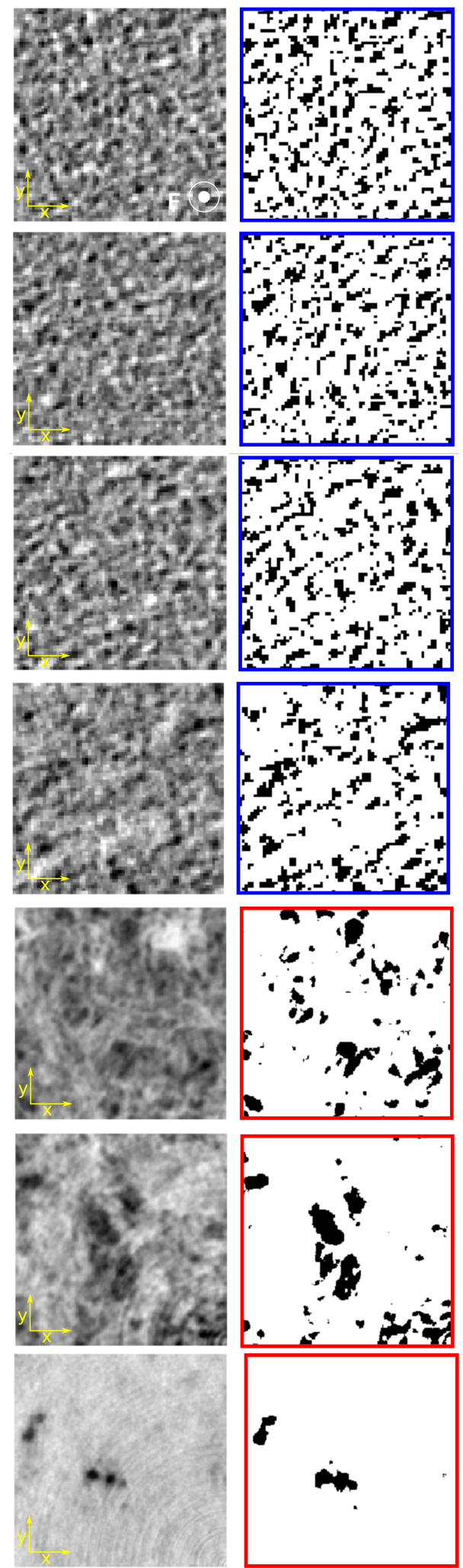

Figure 12: Void morphology evolution along the longitudinal axis (a down to $\mathbf{d}$ for the $0.7 \mu \mathrm{m}$ resolution, and $\mathbf{A}$ down to C for the 0.05 um resolution) in HDPF from the image segmentation method. 
Side views

a

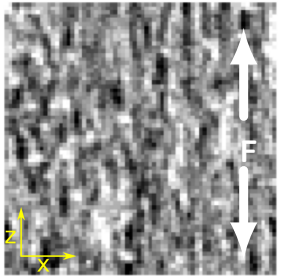

b

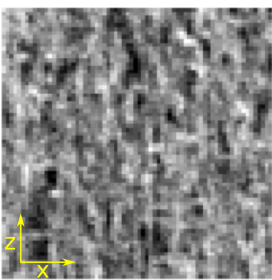

C

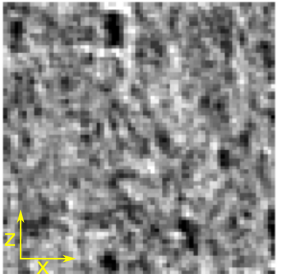

d

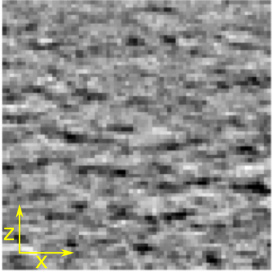

A
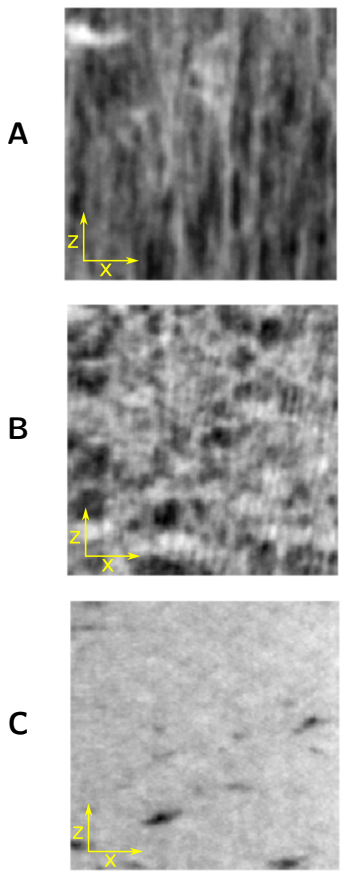
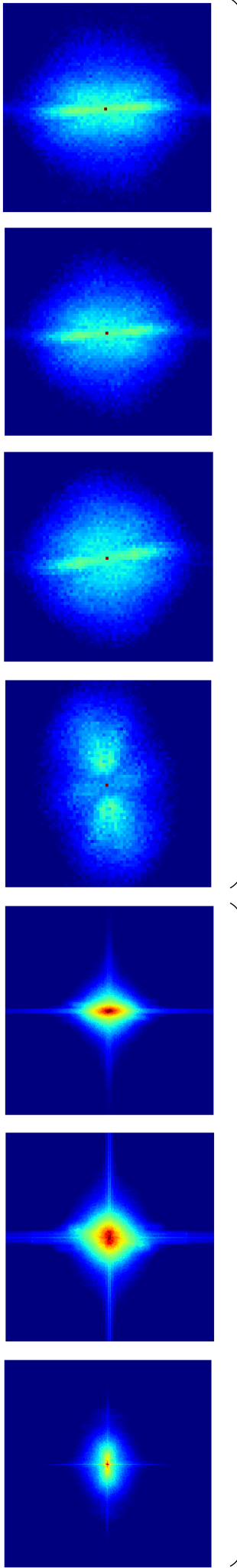

Top views
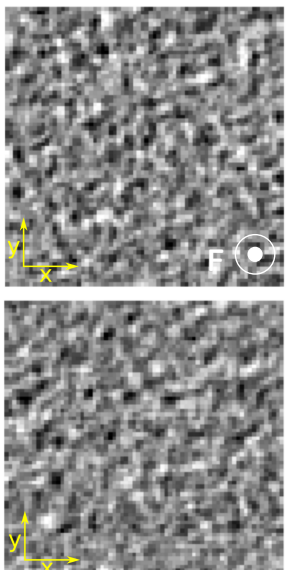

$1 \mathrm{px} \sim 0.7 \mu \mathrm{m}$ $10 \mu \mathrm{m}$ yer.y.
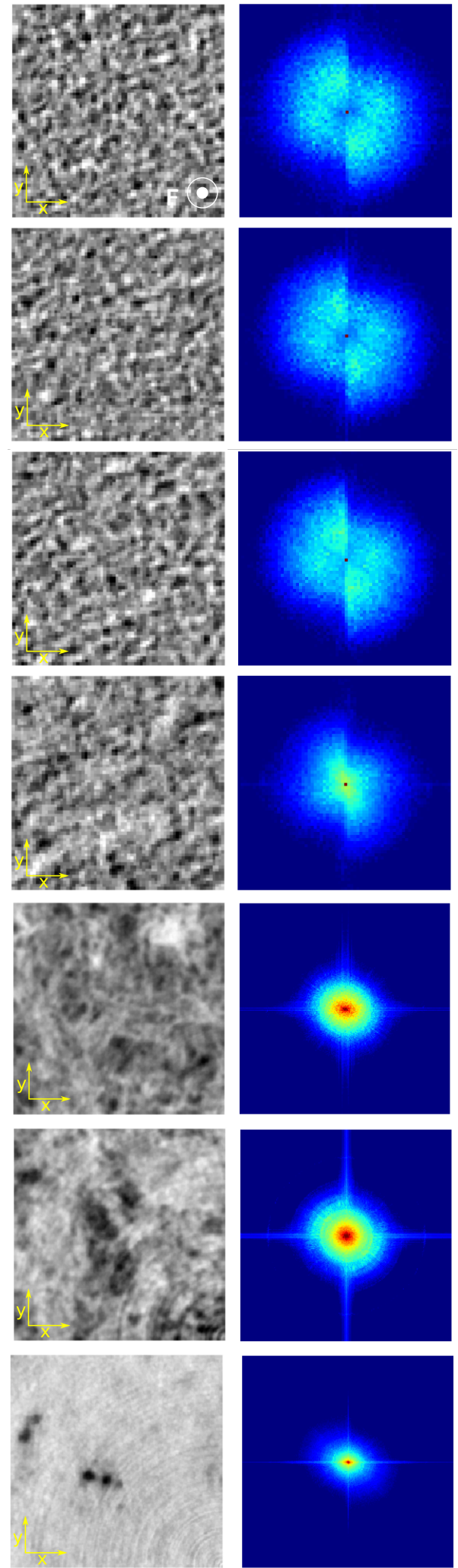

Figure 13: Void morphology evolution along the longitudinal axis (a down to $\mathbf{d}$ for the $0.7 \mu \mathrm{m}$ resolution, and $\mathbf{A}$ down to Ef the 0.05 m 
To give insight about the evolution of the void characteristic dimensions, i.e. height and diameter, along the loading axis, three classical statistical variables can be used: the mean, the median and the mode variables. Details about the limitations of using the mean or the median values can be found in Laiarinandrasana et al. [44]. Actually, in the aforementioned work, the radial and axial evolution of the void diameter and height in a PA6 was studied by means of the mode value. In agreement with the authors, the mode value appears to be a more relevant variable, than the mean and median variables, to characterize the void population distributions; however, the use of a single value to describe an histogram distribution seems very restrictive. Furthermore, the heterogeneous information in a characteristic dimension distribution would be lost. In the present work, taking into account additionally the difficulties associated with the simultaneous study of several histogram distributions, the cumulative frequency evolution was studied.

The evolution of the cumulative frequency distributions of the characteristic dimensions, for the $\mathrm{HDPE}_{0.7}$ and $\mathrm{HDPE}_{0.05}$, from the extended neck region to the end of the neck shoulder is illustrated in Figure 14. Only one SVOI per TVOI was studied: top SVOIs for the $\mathbf{a}$ and A TVOIs, middle SVOIs for the $\mathbf{b}, \mathbf{c}$ and $\mathbf{B}$ TVOIs, and bottom SVOIs for the $\mathbf{d}$ and $\mathbf{C}$ TVOIs. On the one hand, a slight increase of the void diameter, from the extended neck region to the end of the neck shoulder along the loading axis, is expected: a) in the notch edge, see Figure 14.a at the $0.7 \mu \mathrm{m}$ resolution, and b) in the centre of the sample, see Figure 14.c at the $0.05 \mu \mathrm{m}$ resolution. The difference turns to be more significant when the distance to the centre is large enough, e.g. overlapping of the $\mathbf{a}, \mathbf{b}$, and $\mathbf{c}$ curves for the $0.7 \mu \mathrm{m}$ resolution, whereas an appreciably difference is highlighted for the $\mathbf{d}$ curve. Furthermore, a significant gap between the $\mathbf{A}$ curve, at the extended neck region, and the $\mathbf{B}$ and $\mathbf{C}$ curves, at the neck shoulder, for the $0.05 \mu \mathrm{m}$ resolution was observed. On the other hand, a significant reduction of the void height from the centre to the shoulder of the sample, independently on the loading axis position, is highlighted, see Figure 14.b and 14.d respectively for the $0.7 \mu \mathrm{m}$ and the $0.05 \mu \mathrm{m}$ resolution. In order to compare quantitatively the evolution of the cavities characteristics dimensions, the corresponding value for a cumulative probability $f_{c}$ equals to $80 \%$ from the cumulative frequency distributions was determined, see Table 2. The results are in good agreement with the above mentioned trends, i.e. increase of the void diameter and reduction of the void height from the extended neck region to the end of the neck shoulder. It then can be inferred, taking the void volume fraction evolution into account, that the overall deformation of a spherulite in the load direction consisted of volumetric deformation relative to void growth and an extension of the matrix.

To go further, the distribution of the void characteristic dimensions from the cumulative frequency distribution, along the loading axis, was studied. First, the cumulative frequency distribution of the void characteristic dimensions of each SVOI was extracted; then, the corresponding value for a cumulative probability $f_{c}=80 \%$ by the segmentation method was plotted, see Figure 15. The position of the TVOIs, along the longitudinal axis, at low and high resolution was respectively identified by blue (at the top) and red lines (at the bottom) outside the figures. The evolution of both the diameter and the height follows the same trend independently of the scans resolution according respectively to Figures 15.a and 15.b. In line with previous observations, the void diameter increases slightly from the extended neck region to the end of the neck shoulder whereas a significant void height decrease was observed. The superposition of the evolution of both void characteristics was used to estimate the position, along the loading axis, of the transition between a prolate to an oblate spheroidal geometry, as illustrated by Figure 15.c. The transition was located at about 0.78 at the $0.7 \mu \mathrm{m}$ resolution (see blue dashed line), whereas it was located at about 0.85 at the $0.05 \mu \mathrm{m}$ resolution (see red dashed line). Second, using a similar procedure to the one used by the segmentation method, the evolution of the void characteristic dimensions by the FFT analysis was studied, see Figure 16. Contrary to the segmentation method results, a significant void diameter increase, by the FFT analysis, can be observed in Figure 16.a. Moreover, an abrupt void diameter decrease, at the end of the neck shoulder, was clearly noticed. Indeed, the maximum void diameter was found at about $z / \delta=0.96$ and $z / \delta=0.92$, respectively at low and high resolution. Besides, in line with the segmentation method results, a significant void height decrease was observed, see Figure 16.b. From Figure 16.c it can be seen that the transition, from a prolate to an oblate spheroidal geometry, was located at about 0.78 at the $0.7 \mu \mathrm{m}$ resolution (see blue dashed line), whereas it was located at about 0.86 at the $0.05 \mu \mathrm{m}$ resolution (see red dashed line). Accordingly, no difference is observed depending on the image treatment method, for scans with the same resolution; however, using different scan resolutions, a negligible difference was noticed. It can therefore be concluded that the transition was located in a plane at the beginning of the neck shoulder.

\subsubsection{Comparative study of the void volume fraction in $H D P E$}

The normalized void volume fraction from the image segmentation method, at the $0.7 \mu \mathrm{m}$ (unfilled blue squares) and $0.05 \mu \mathrm{m}$ resolution (unfilled red circles), was plotted against the normalized axial coordinate $z / \delta$ in Figure 17. 


\section{Table 2}

Cavities characteristic dimensions evolution, from the cumulative frequency distribution for a cumulative probability $f_{c}=0.8$, from the extended neck region to the end of the neck shoulder, i.e. from a down to $\mathbf{d}$ and from $\mathrm{A}$ down to $\mathrm{C}$ respectively at low and high resolution.

\begin{tabular}{llllllll}
\hline & a & b & c & d & A & B & C \\
\hline Diameter $($ in $\mu \mathrm{m})$ & 4.2 & 4.3 & 4.3 & 5.2 & 0.4 & 0.6 & 0.7 \\
\hline Height $($ in $\mu \mathrm{m})$ & 9 & 7 & 5 & 3 & 0.8 & 0.4 & 0.2 \\
\hline
\end{tabular}
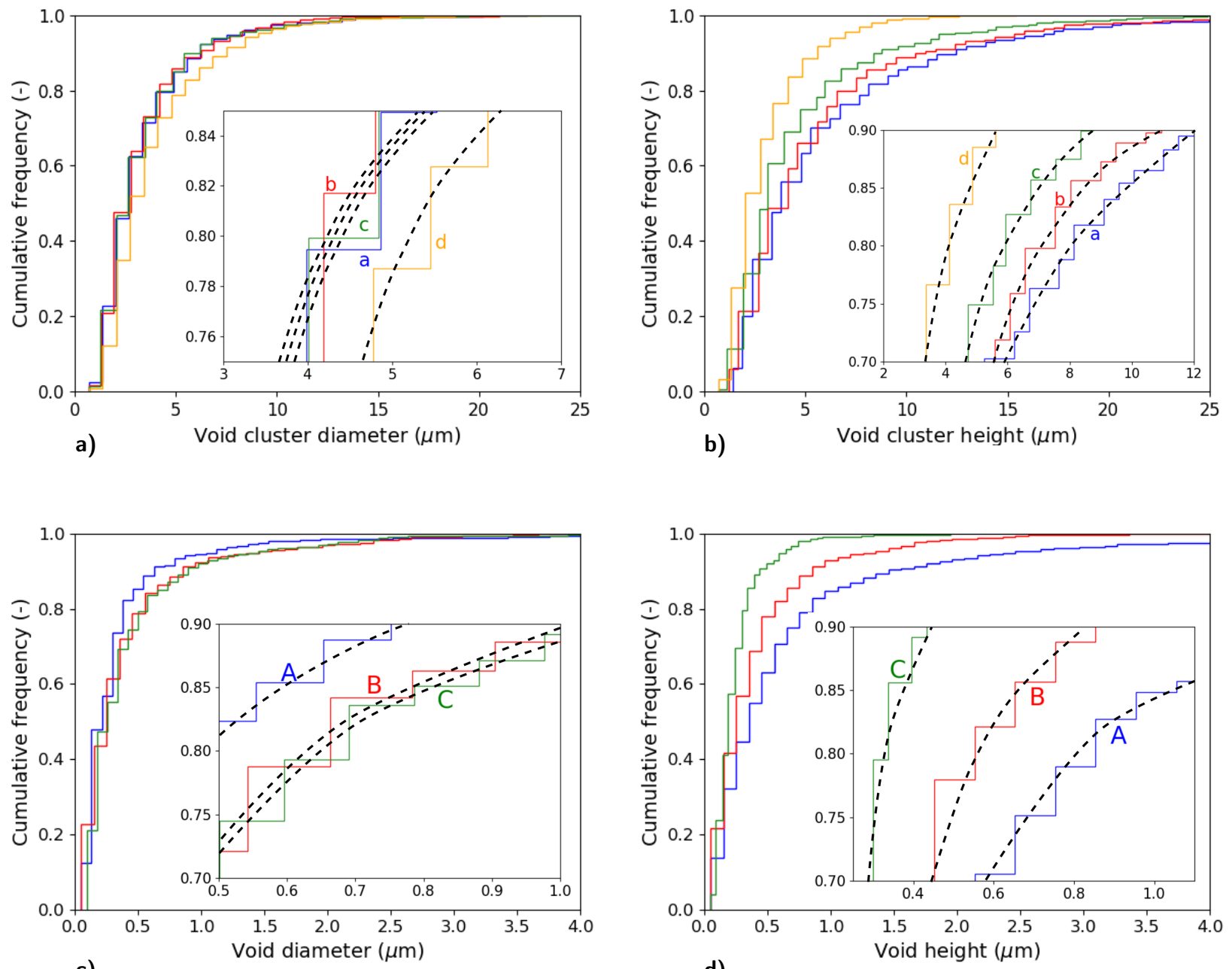

c)

d)

Figure 14: Cumulative frequency distribution from image segmentation. $0.7 \mu \mathrm{m}$ resolution: a) voids cluster diameter, and b) height; and $0.05 \mu \mathrm{m}$ resolution: c) void diameter, and d) height.

The $\mathrm{HDPE}_{0.7}$ curve is parabolic and flattened in the centre. The evidence suggests that the $\mathrm{HDPE}_{0.05}$ curve follows the same trend, i.e. three zones can be identified within the sample: i) slight reduction in the centre of the net section, i.e. $0 \leq z / \delta \leq 0.6$; ii) marked reduction when the distance to the centre is large enough, i.e. $z / \delta \geq 0.8$; and iii) negligible cavitation at the end of the neck shoulder, i.e. $z / \delta \rightarrow 1$. It should, however, be noted that an appreciable difference between both curves, within $0.6 \leq z / \delta \leq 0.9$, is highlighted. In line with previous observations on deformed semicrystalline polyamide $6[44,46,47]$, the difference could be related with the deformation heterogeneity or gradient 

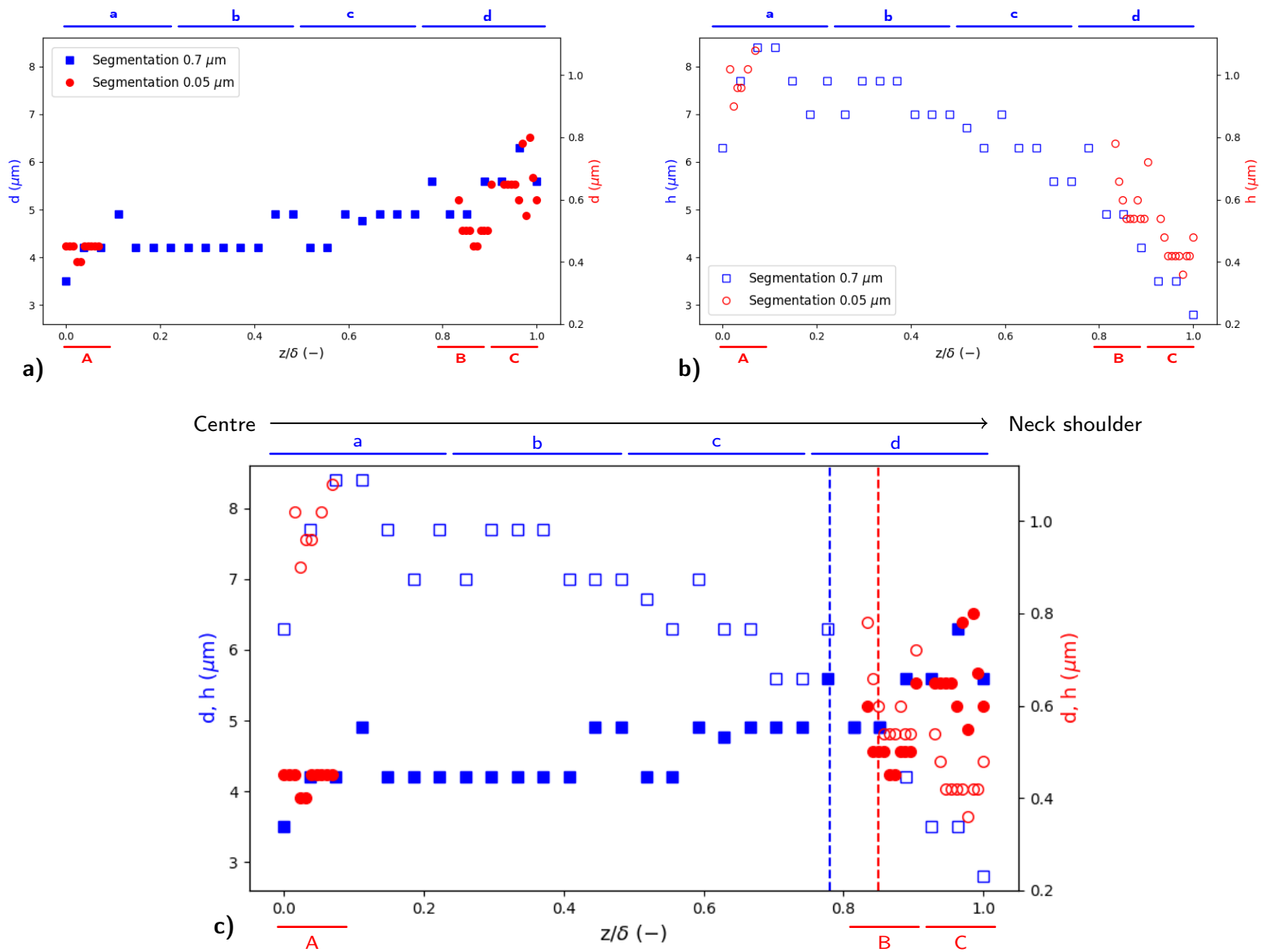

Figure 15: Cavities characteristic dimensions evolution from the image segmentation method between microtomographied (in blue) and nanotomographied HDPE (in red): a) Diameter; b) Height; and c) Transition zone, i.e. cavities turned from a prolate to an oblate morphology.

through the width of the sample. However, consistent with previous results on Polyamide 6 [14, 45] and Polyamide 11 [21], the results confirm the longitudinal void volume evolution in HDPE, independently on the radiation tomography resolution. Moreover, in line with Selles et al. [45], the whitened zone in the test sample was less extended than the damaged zone, see Figure 3. Besides, it was not completely clear why the evolution of the void volume fraction in a single TVOI at low resolution from the extended neck region to the beginning of the neck shoulder, i.e. from a down to $\mathbf{c}$, follows a parabolic trend; nevertheless, this effect is only local.

\subsubsection{Comparative study of the axial Anisotropy Index $\left(A_{Z}\right)$ of cavities in HDPE}

In Figure 18 the evolution of the axial anisotropy index $A_{Z}$ from the segmentation method, at the $0.7 \mu \mathrm{m}$ (unfilled blue squares) and $0.05 \mu \mathrm{m}$ resolution (unfilled red circles), was plotted against the normalized axial coordinate $z / \delta$. The image segmentation results provide a substantial evidence of the gradual change of the axial void shape from the extended neck region $z / \delta=0$ to the end of the neck shoulder $z / \delta=1$, in the neck root and the centre of the sample, respectively from a down to $\mathbf{d}$ and from $\mathbf{A}$ down to $\mathbf{C}$. The $\mathrm{HDPE}_{0.7}$ curve is parabolic and flattened in the centre. The results suggest that the $\mathrm{HDPE}_{0.05}$ curve follows the same trend, i.e. a positive value in the extended neck region of the test sample and a slow decreasing of the $\mathrm{A}_{Z}$ value towards a negative one at the shoulder of the sample. In line with Poulet et al. [21], three regions, related with the void morphology, can be identified within the sample: i) prolate voids, i.e. elongated in the loading direction, in the extended neck region of the sample, respectively $0 \leq z / \delta<0.78$ and 

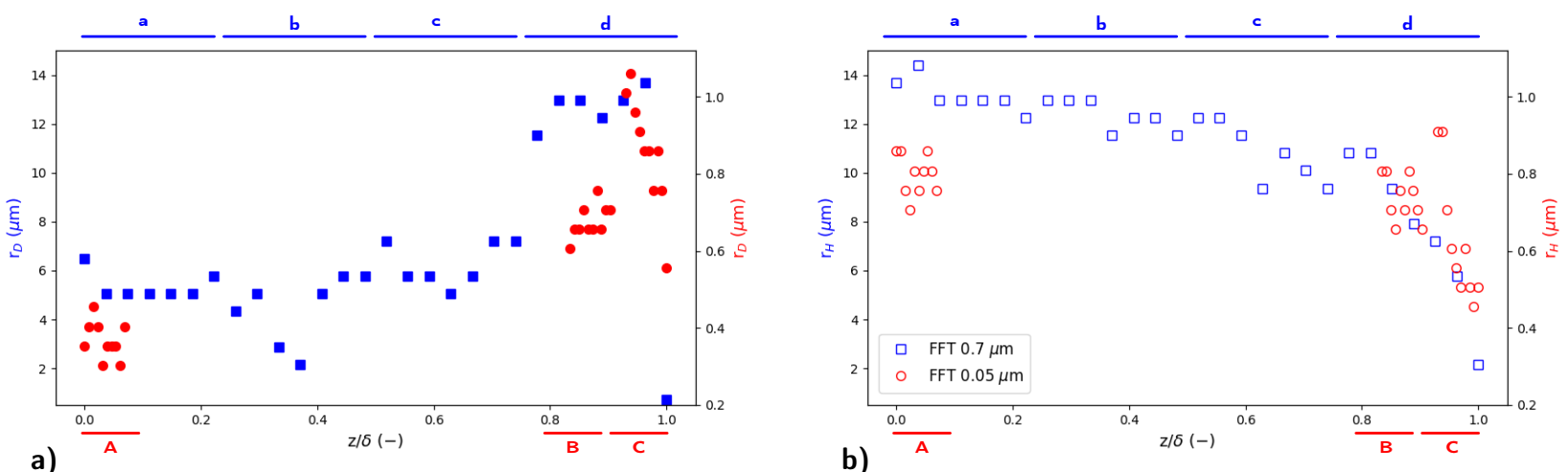

b)

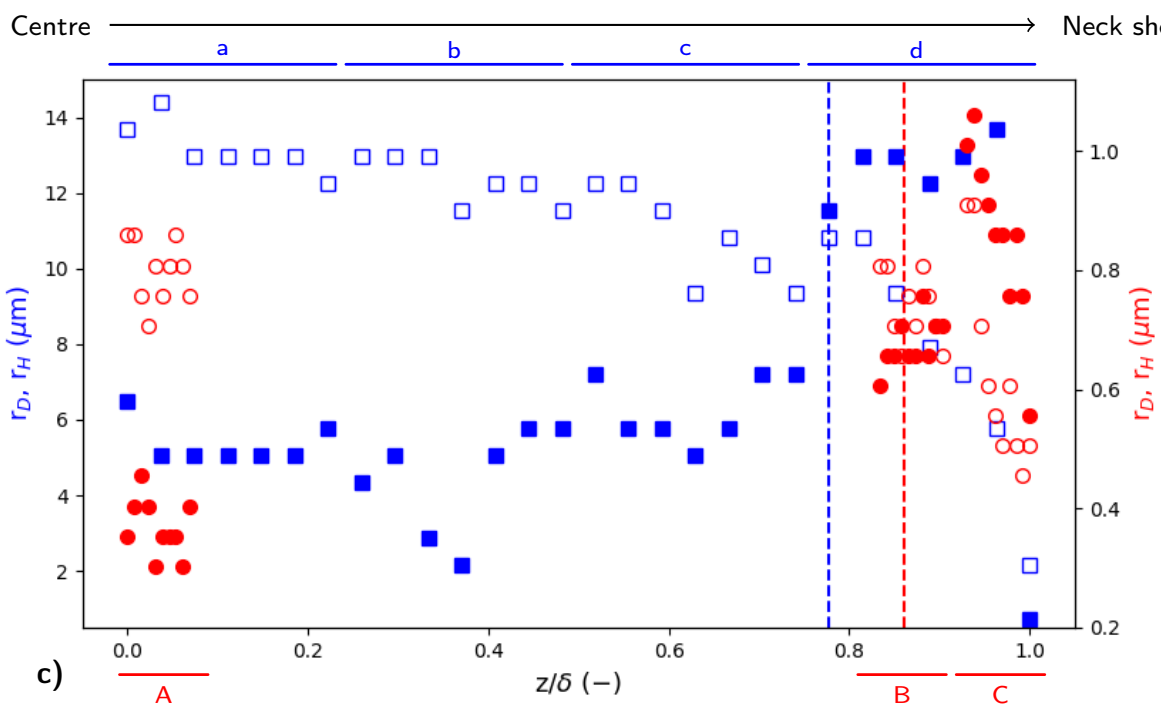

Figure 16: Cavities characteristic dimensions evolution from the FFT protocol between microtomographied (in blue) and nanotomographied HDPE (in red): a) Diameter; b) Height; and c) Transition zone, i.e. cavities turned from a prolate to an oblate morphology.

$0 \leq z / \delta<0.86$ at low and high resolution; ii) spheroidal voids, i.e. height similar to both diameters, in a transition zone between the extended neck region and the beginning of the neck shoulder of the sample, when the distance to the centre is large enough, respectively $z / \delta \cong 0.78$ and $z / \delta \cong 0.86$ at low and high resolution; and iii) oblate voids, i.e. elongated perpendicularly to the loading direction, at the end of the neck shoulder of the sample, respectively $z / \delta>0.78$ and $z / \delta>0.86$ at low and high resolution. A slight inversion of the anisotropy index curve, at the end of the neck shoulder $z / \delta \cong 0.97$, was observed at the $0.05 \mu \mathrm{m}$ resolution; however, no significant void morphology evolution, i.e. oblate spheroidal geometry, is expected. Associated with the cavities characteristics dimensions evolution (see Figure 15), the sudden change of the anisotropy index could be related with a slight increase of the void height at the end of the neck shoulder.

In Figure 19 the evolution of the Anisotropy Index from the FFT analysis, at the $0.7 \mu \mathrm{m}$ (filled blue squares) and $0.05 \mu \mathrm{m}$ resolution (filled red circles), was plotted against the normalized axial coordinate $z / \delta$. Both evolution curves seems to follow the same parabolic trend along the loading axis, i.e. $\mathrm{A}_{Z}$ is constant and positive when $0 \leq z / \delta<0.6$ and abruptly diminishes towards a negative value at $z / \delta>0.8$ and $z / \delta>0.9$, respectively at low and high resolution. In agreement with the segmentation method results, a transition from a prolate to an oblate spheroidal geometry, from the extended neck region to the end of the shoulder of the test sample, was evidenced independently on the scan resolution, respectively $z / \delta \cong 0.78$ and $z / \delta \cong 0.91$ at low and high resolution. The transition zone, i.e. transition from a prolate to an oblate morphology $A_{z}=0$, was clearly captured by the $0.05 \mu \mathrm{m}$ resolution (see $\mathbf{B}$ in Figure 13). 


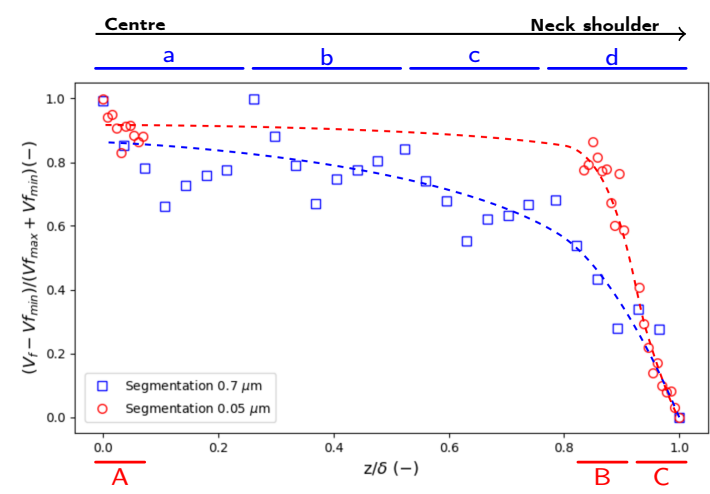

Figure 17: Normalized void volume fraction evolution from the image segmentation method between microtomographied (in blue) and nanotomographied HDPE (in red).

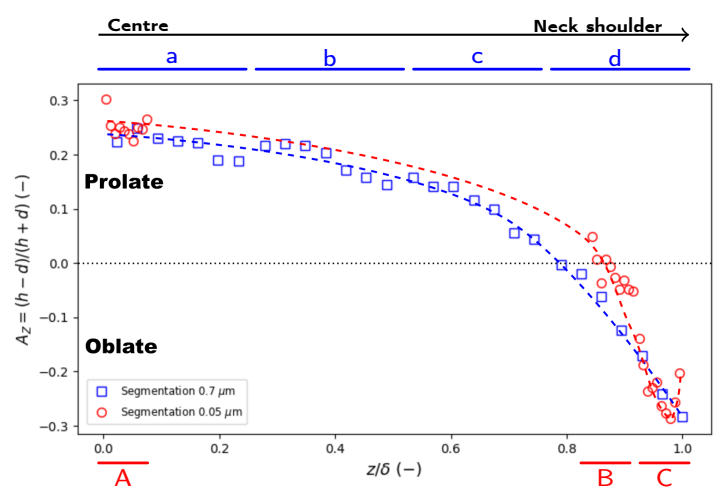

Figure 18: Axial anisotropy index evolution from the image segmentation method between microtomographied (in blue) and nanotomographied HDPE (in red).

It seems that the $\mathrm{HDPE}_{0.7}$ curve from the FFT analysis is more flattened in the centre than the $\mathrm{HDPE}_{0.7}$ curve from the segmentation method; however, in line with previous comments, three regions, related with the void morphology, were clearly identified. Besides, a significant inversion of the anisotropy index curve, at the end of the neck shoulder respectively $z / \delta \cong 0.96$ and $z / \delta \cong 0.97$ at low and high resolution, was observed independently on the scan resolution. Indeed, a transition from oblate to prolate and from oblate to spheroidal was highlighted respectively at the $0.7 \mu \mathrm{m}$ and $0.05 \mu \mathrm{m}$ resolution. It should be mentioned that the lowest void volume fraction is located at the end of the neck shoulder $z / \delta \cong 1$; then, even that the cavities return to the same morphology than the one observed at the centre of the sample, the cavities dimensions are much lower.

Finally, in an attempt to study, independently of the 3D imaging treatment, the evolution of the axial anisotropy index, from both the segmentation method and the FFT analysis, the normalized anisotropy index $A_{z} / A_{z(\max )}$ along the normalized axial coordinate $z / \delta$ was plotted in Figure 20. $A_{z(\max )}$ is the corresponding maximum anisotropy index. The results seems to follow a parabolic trend. Furthermore, the normalized anisotropy index curves are overlapped along the loading axis. Independently on the treatment method and the image resolution, a transition from a prolate to an oblate spheroidal geometry was highlighted. The transition zone was located at about 0.78 and 0.9 respectively for the $0.7 \mu \mathrm{m}$ and $0.05 \mu \mathrm{m}$ resolution. Indeed, concerning the location of the transition zone, it seems that the results are solely resolution-dependent values as no significant difference was observed using two different image treatment methods. However, the sudden inversion of the anisotropy index at the end of the neck shoulder $z / \delta \cong 0.96$ was clearly observed in the results of the FFT technique. The anisotropy index inversion was also observed, at the end of the neck shoulder $z / \delta \cong 0.96$, in the results of the segmentation method at the $0.05 \mu \mathrm{m}$ resolution but at a lower scale. As a matter of fact, no inversion was observed in the results of the segmentation method at the $0.7 \mu \mathrm{m}$ resolution, presumably associated with both the user-dependent imaging treatment and the resolution level. 


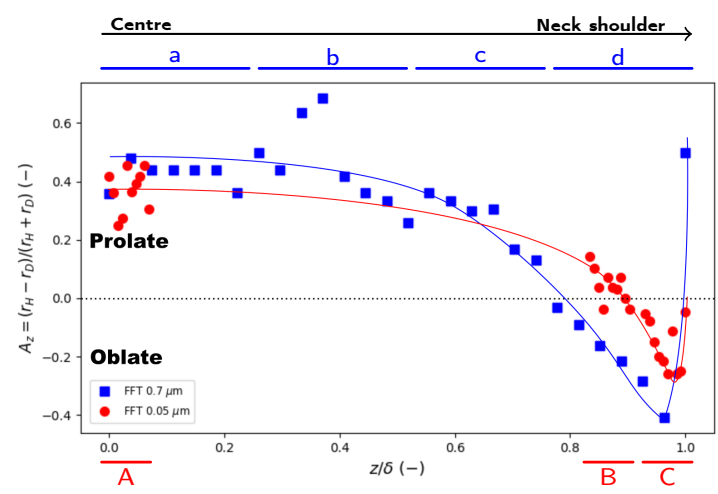

Figure 19: Axial anisotropy index evolution from the FFT protocol between microtomographied (in blue) and nanotomographied HDPE (in red).

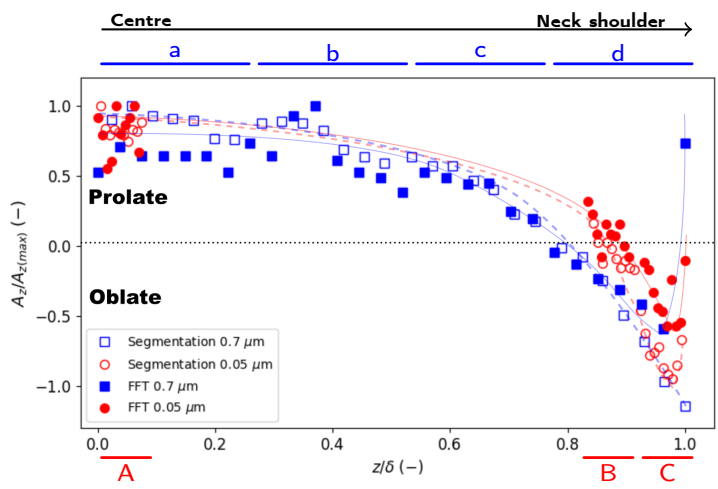

Figure 20: Normalized axial anisotropy index evolution from the image segmentation method (unfilled symbols) and the FFT protocol (filled symbols) between microtomographied (in blue) and nanotomographied HDPE (in red).

The results are qualitatively similar to those of earlier studies [16]. The cavitation state observed at the extended neck region $z / \delta<0.8$ was the most advanced voiding within the sample whereas, near the end of the neck shoulder $z / \delta>0.8$, the cavitation state depicts the most advanced voiding states encountered at a given deformation before the end-of-the-first-softening displacement. Besides, the axial anisotropy evolution of damage features in a HDPE for different tensile deformations was shown in Blaise et al. [22]. Anisotropy index was slightly higher than zero in the undeformed state, linked with the anisotropy induced by the direction of the extrusion process, then a decrease till a negative value, i.e. oblate spheroidal geometry, was shown. Finally, for large strains, the index reverses to cross the zero level and a strong increase, i.e. prolate spheroidal geometry, was highlighted. It could be inferred therefore that the axial evolution of the cavitation state and the void morphology highlights the local deformation level, i.e. along the revolution axis of the sample the whole story of deformation is captured.

\section{Conclusion}

Prior works have documented the macromolecular rearrangement without any cavitation, at the microscopic scale, in deformed High Density PolyEthylene (HDPE). In the present study, magnified synchrotron radiation holotomography was used to highlight the existence of permanent nano-cavities within the spherulitic microstructure of HDPE.

A flat notched sample of semicrystalline HDPE was deformed under steady crosshead speed up to the end of the first stress softening. The microstructure and the voiding state in the unloaded sample was observed in 3D using x-ray tomography. Two parallel regions were studied: four locations of interest near the notch edge and three locations of interest centred on the longitudinal axis with two spatial resolutions differing by one order of magnitude, $0.7 \mu \mathrm{m}$ and $0.05 \mu \mathrm{m}$, using classical synchrotron parallel beam microtomography and magnified holotomography, respectively. 
Tomographic inspections of deformed HDPE samples suggested the presence of two populations of voids: a) nucleated from inclusions, and b) void nucleation within equatorial and polar fans due to the spherulitic structure. In agreement with previous results on notched round samples during interrupted tensile test on semicrystalline PA6 at a $0.7 \mu \mathrm{m}$ resolution, HDPE cavitation seemed to follow the same trend, but at a different scale:

- Cavities were arranged in columns and orientated towards the loading axis.

- When the distance to the centre of the sample is large enough, cavities were in a penny-shaped configuration, i.e. in the top view, cavities have a circular shape whereas, in the side view, cavities are represented by stripes.

- Polar fan axis followed the surface orientation near the neck surface.

- Reduction in void diameter when approaching the neck surface, associated with the geometry-related radial stress gradient.

Besides, although the void lateral dimension seems larger, for the notched sample, than on a smooth sample [25], the observations are consistent as a higher stress triaxiality ratio, on the notched sample, can be expected. Same observations on PA6 were already discussed [17, 44].

Using two different procedures at both the real intensity and the reciprocal space, respectively by image segmentation and 2D Fast Fourier Transforms (FFT), a quantitative study of the evolution of the cavities characteristic dimensions was performed. Both methods highlighted a transition of the void morphology, from the extended neck region to the neck shoulder, from a prolate to an oblate spheroidal geometry.

Employing the cumulative frequency, the evolution of both the void cluster and void characteristic dimensions, from the extended neck region to the neck shoulder of the sample along the loading axis, was studied. While a slight increment of the void cluster and void diameter was seen, a significant reduction of the height was evidenced. Presumably due to low resolution from x-ray microtomography, i.e. resolution limit close to the size of damage features, both the diameter and height of the voided zones appears to be greater than the mean diameter of the spherical spherulite identified in the undeformed material. It might also be possible that two spherulite cracks coalesce in our notched sample, as stress triaxiality at the neck region is high. Then, the overall deformation of a spherulite consisted of volumetric deformation relative to void growth and extension of the matrix. Finally, the anisotropy index, i.e. the shape ratio between height and diameter, was studied from both the segmentation method and the FFT analysis. The results provide compelling evidence of morphology transition of cavities within the test sample from a prolate to an oblate geometry, distributed respectively in the extended neck region and at the neck shoulder. A sudden inversion of the anisotropy index, i.e. a transition from oblate to prolate or from oblate to spheroidal, respectively at the $0.7 \mu \mathrm{m}$ and at the $0.05 \mu \mathrm{m}$ resolution, at the end of the neck shoulder, was clearly observed.

A scenario of cavitation under tension loading can be therefore outlined: nucleation of voids either on a) impurities or, mostly, b) via cracks, within the equatorial and polar fans, in the spherulite, and subsequently grow in the loading direction while slightly shrink in the radial directions. Furthermore, it might also be possible that two spherulite cracks coalesce as stress triaxiality is high, linked to the geometry of the notched sample. The aforementioned scenario was highlighted along the revolution axis of the sample, where the whole story of deformation was captured.

\section{Acknowledgement}

The authors acknowledge ESRF for beamtime in experiment MA1647.

\section{CRediT authorship contribution statement}

Cristian Ovalle: Conceptualization, Formal analysis, Investigation, Visualization, Writing - Original Draft, Writing - Review \& Editing. Peter Cloetens: Methodology. Henry Proudhon: Methodology, Software, Writing - Review \& Editing. Thilo F Morgeneyer: Methodology, Writing - Review \& Editing. Lucien Laiarinandrasana: Writing Review \& Editing, Supervision.

\section{References}

[1] S. S. Sternstein, F. A. Myers, Yielding of glassy polymers in the second quadrant of principal stress space, Journal of Macromolecular Science, Part B 8 (1973) 539-571 
[2] Z. Bartczak, A. Galeski, A. Argon, R. Cohen, On the plastic deformation of the amorphous component in semicrystalline polymers, Polymer 37 (1996) 2113-2123.

[3] F. Zairi, M. Naït-Abdelaziz, K. Woznica, J.-M. Gloaguen, Constitutive equations for the viscoplastic-damage behaviour of a rubber-modified polymer, European Journal of Mechanics - A/Solids 24 (2005) 169 - 182.

[4] E. Ghorbel, A viscoplastic constitutive model for polymeric materials, International Journal of Plasticity 24 (2008) $2032-2058$.

[5] K. Hasanpour, S. Ziaei-Rad, M. Mahzoon, A large deformation framework for compressible viscoelastic materials: Constitutive equations and finite element implementation, International Journal of Plasticity 25 (2009) $1154-1176$.

[6] C. G'Sell, S.-L. Bai, J.-M. Hiver, Polypropylene/polyamide 6/polyethylene-octene elastomer blends. part 2: volume dilatation during plastic deformation under uniaxial tension, Polymer 45 (2004) 5785-5792.

[7] P. Bridgman, Studies in large plastic flow and fracture with special emphasis on the effects of hydrostatic pressure, 1952.

[8] A. Pawlak, A. Galeski, Plastic deformation of crystalline polymers: The role of cavitation and crystal plasticity, Macromolecules 38 (2005) 9688-9697.

[9] F. Addiego, A. Dahoun, C. G'Sell, J.-M. Hiver, Characterization of volume strain at large deformation under uniaxial tension in high-density polyethylene, Polymer 47 (2006) 4387-4399.

[10] A. Pawlak, A. Galeski, Cavitation during tensile deformation of polypropylene, Macromolecules 41 (2008) $2839-2851$.

[11] Z. Bartczak, A. Argon, R. Cohen, Texture evolution in large strain simple shear deformation of high density polyethylene, Polymer 35 (1994) 3427-3441.

[12] A. Pawlak, Cavitation during tensile deformation of high-density polyethylene, Polymer 48 (2007) 1397-1409.

[13] L. Laiarinandrasana, T. F. Morgeneyer, H. Proudhon, C. Regrain, Damage of semicrystalline polyamide 6 assessed by $3 \mathrm{~d}$ x-ray tomography: From microstructural evolution to constitutive modeling, Journal of Polymer Science Part B: Polymer Physics 48 (2010) 1516-1525.

[14] L. Laiarinandrasana, T. F. Morgeneyer, H. Proudhon, F. N'guyen, E. Maire, Effect of multiaxial stress state on morphology and spatial distribution of voids in deformed semicrystalline polymer assessed by x-ray tomography, Macromolecules 45 (2012) $4658-4668$.

[15] H.-A. Cayzac, K. Saï, L. Laiarinandrasana, Damage based constitutive relationships in semi-crystalline polymer by using multi-mechanisms model, International Journal of Plasticity 51 (2013) $47-64$.

[16] N. Selles, P. Cloetens, H. Proudhon, T. F. Morgeneyer, O. Klinkova, N. Saintier, L. Laiarinandrasana, Voiding mechanisms in deformed polyamide 6 observed at the nanometric scale, Macromolecules 50 (2017) 4372-4383.

[17] L. Laiarinandrasana, N. Selles, O. Klinkova, T. F. Morgeneyer, H. Proudhon, L. Helfen, Structural versus microstructural evolution of semicrystalline polymers during necking under tension: Influence of the skin-core effects, the relative humidity and the strain rate, Polymer Testing 55 (2016) $297-309$.

[18] S. Castagnet, S. Girault, J. Gacougnolle, P. Dang, Cavitation in strained polyvinylidene fluoride: mechanical and x-ray experimental studies, Polymer 41 (2000) $7523-7530$.

[19] M. Challier, J. Besson, L. Laiarinandrasana, R. Piques, Damage and fracture of polyvinylidene fluoride (pvdf) at $20^{\circ} \mathrm{c}$ : Experiments and modelling, Engineering Fracture Mechanics 73 (2006) 79 - 90.

[20] G. Boisot, L. Laiarinandrasana, J. Besson, C. Fond, G. Hochstetter, Experimental investigations and modeling of volume change induced by void growth in polyamide 11, International Journal of Solids and Structures 48 (2011) $2642-2654$.

[21] P.-A. Poulet, G. Hochstetter, A. King, H. Proudhon, S. Joannès, L. Laiarinandrasana, Observations by in-situ x-ray synchrotron computed tomography of the microstructural evolution of semi-crystalline polyamide 11 during deformation, Polymer Testing 56 (2016) 245 - 260.

[22] A. Blaise, C. Baravian, S. Andre, J. Dillet, L. J. Michot, R. Mokso, Investigation of the mesostructure of a mechanically deformed hdpe by synchrotron microtomography, Macromolecules 43 (2010) 8143-8152.

[23] A. Pawlak, A. Galeski, Cavitation during tensile drawing of annealed high density polyethylene, Polymer 51 (2010) 5771-5779.

[24] L. Farge, S. André, F. Meneau, J. Dillet, C. Cunat, A common multiscale feature of the deformation mechanisms of a semicrystalline polymer, Macromolecules 46 (2013) 9659-9668.

[25] T. F. Morgeneyer, H. Proudhon, P. Cloetens, W. Ludwig, Q. Roirand, L. Laiarinandrasana, E. Maire, Nanovoid morphology and distribution in deformed hdpe studied by magnified synchrotron radiation holotomography, Polymer 55 (2014) 6439-6443.

[26] A. Krajenta, A. Rozanski, R. Idczak, Morphology and properties alterations in cavitating and non-cavitating high density polyethylene, Polymer 103 (2016) 353-364. New Polymeric Materials and Characterization Methods for Water Purification.

[27] C. Devilliers, B. Fayolle, L. Laiarinandrasana, S. Oberti, E. Gaudichet-Maurin, Kinetics of chlorine-induced polyethylene degradation in water pipes, Polymer degradation and stability 96 (2011) 1361-1368.

[28] L. Laiarinandrasana, C. Devilliers, S. Oberti, E. Gaudichet, B. Fayolle, J. Lucatelli, Ring tests on high density polyethylene: Full investigation assisted by finite element modeling, International Journal of Pressure Vessels and Piping 88 (2011) 1-10.

[29] L. Laiarinandrasana, C. Devilliers, J. M. Lucatelli, E. Gaudichet-Maurin, J. M. Brossard, Experimental study of the crack depth ratio threshold to analyze the slow crack growth by creep of high density polyethylene pipes, International Journal of Pressure Vessels and Piping 122 (2014) 22-30.

[30] G. T. Davis, R. K. Eby, Glass transition of polyethylene: Volume relaxation, Journal of Applied Physics 44 (1973) $4274-4281$.

[31] S.-S. Chang, Thermal relaxation and glass transition in polyethylene, Journal of Polymer Science: Polymer Symposia 43 (1973) $43-54$.

[32] P. J. Hendra, H. P. Jobic, K. Holland-Moritz, Low temperature crystallization in polyethylene and the value of tg, Journal of Polymer Science: Polymer Letters Edition 13 (1975) 365-368.

[33] C. Devilliers, Degradation chimique du PE et influence sur le comportement, l'endommagement et la rupture en fluage : application à la durabilité des canalisations sous pression (in French), Ph.D. thesis, Ecole Nationale Supérieure des Mines de Paris, 2011.

[34] E. Euchler, R. Bernhardt, K. Schneider, G. Heinrich, S. Wießner, T. Tada, In situ dilatometry and x-ray microtomography study on the formation and growth of cavities in unfilled styrene-butadiene-rubber vulcanizates subjected to constrained tensile deformation, Polymer 187 (2020) 122086.

[35] H. Kwon, P.-Y. Jar, New energy partitioning approach to the measurement of plane-strain fracture toughness of high-density polyethylene 
based on the concept of essential work of fracture, Engineering Fracture Mechanics 74 (2007) $2471-2480$.

[36] A. S. Ognedal, A. H. Clausen, A. Dahlen, O. S. Hopperstad, Behavior of pvc and hdpe under highly triaxial stress states: An experimental and numerical study, Mechanics of Materials 72 (2014) $94-108$.

[37] S. Na, S. Spatari, Y. G. Hsuan, Fracture characterization of pristine/post-consumer hdpe blends using the essential work of fracture (ewf) concept and extended finite element method (xfem), Engineering Fracture Mechanics 139 (2015) 1 - 17.

[38] E. Maire, P. J. Withers, Quantitative x-ray tomography, International Materials Reviews 59 (2014) 1-43.

[39] G. Requena, P. Cloetens, W. Altendorfer, C. Poletti, D. Tolnai, F. Warchomicka, H. P. Degischer, Sub-micrometer synchrotron tomography of multiphase metals using kirkpatrick-baez optics, Scripta Materialia 61 (2009) 760-763.

[40] P. Bleuet, P. Cloetens, P. Gergaud, D. Mariolle, N. Chevalier, R. Tucoulou, J. Susini, A. Chabli, A hard x-ray nanoprobe for scanning and projection nanotomography, Review of Scientific Instruments 80 (2009) 056101.

[41] R. Schirrer, C. Fond, A. Lobbrecht, Volume change and light scattering during mechanical damage in polymethylmethacrylate toughened with core-shell rubber particles, Journal of Materials Science 31 (1996) 6409-6422.

[42] S. Muhammad, P.-Y. Jar, Determining stress-strain relationship for necking in polymers based on macro deformation behavior, Finite Elements in Analysis and Design 70-71 (2013) $36-43$.

[43] J. Ye, S. André, L. Farge, Kinematic study of necking in a semi-crystalline polymer through 3d digital image correlation, International Journal of Solids and Structures 59 (2015) $58-72$.

[44] L. Laiarinandrasana, O. Klinkova, F. Nguyen, H. Proudhon, T. F. Morgeneyer, W. Ludwig, Three dimensional quantification of anisotropic void evolution in deformed semi-crystalline polyamide 6, International Journal of Plasticity 83 (2016) 19 - 36.

[45] N. Selles, F. Nguyen, T. F. Morgeneyer, H. Proudhon, W. Ludwig, L. Laiarinandrasana, Comparison of voiding mechanisms in semi-crystalline polyamide 6 during tensile and creep tests, Polymer Testing 49 (2016) $137-146$.

[46] N. Selles, N. Saintier, L. Laiarinandrasana, Voiding mechanisms in semi-crystalline polyamide 6 during creep tests assessed by damage based constitutive relationships and finite elements calculations, International Journal of Plasticity 86 (2016) $112-127$.

[47] Y. Cheng, L. Laiarinandrasana, L. Helfen, H. Proudhon, O. Klinkova, T. Baumbach, T. F. Morgeneyer, 3d damage micromechanisms in polyamide 6 ahead of a severe notch studied by in situ synchrotron laminography, Macromolecular Chemistry and Physics 217 (2016) $701-$ 715 . 